\title{
الرؤية التوحيدية وصلتها بالتكامل المعرفي عند محمد إقبال
}

\section{*} عبد الحليم مهورباشة

\author{
الملخص \\ تقوم هذه الدراسة على استنباط مفهوم الرؤية التوحيدية عند محمد إقبال في كتابه "تحديـــ

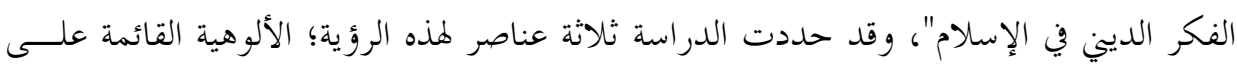

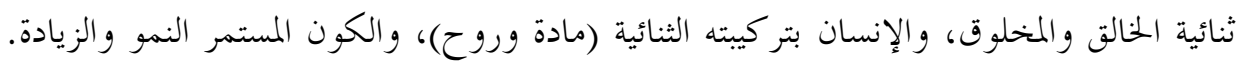

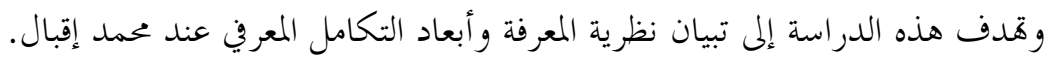 \\ الكلمات المفتاحية: الرؤية التوحيدية، التكامل المعرفي، روح القرآن، وحدة الحقيقة.
}

\section{Muhammad Iqbal's Monotheistic Vision and its Relation to Integration of Knowledge}

\begin{abstract}
This paper is based on Mohammad Iqbal's effort to derive the concept of Tawhidi (monotheistic \} vision in his book "Reconstruction of Religious Thought in Islam". It identifies three elements of this vision; divinity based on the duality of the creator and the created, duality of matter and spirit of Mankind and the continuous growth and expansion of the universe. This study aims to demonstrate the theory of knowledge and the dimensions of epistemological integration developed by Muhammad Iqbal.
\end{abstract}

Keywords: Monotheistic vision, Knowledge integration, Spirit of the Quran, Unity of truth.

$$
\text { " دكتوراه العلوم في علم الاجتما ع، أستاذ محاضر بقسم علم الاجتماع، جامعة سطيف r. Halimbacha680.fr }
$$


مقدمة:

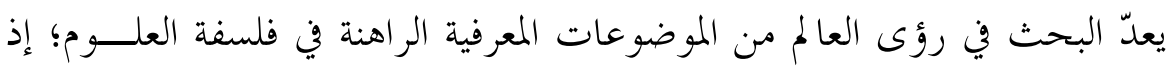

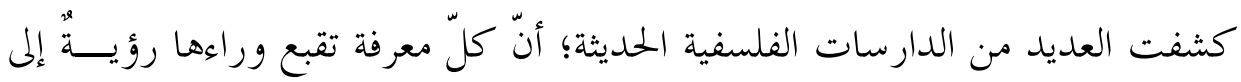
العالم، تتمثل وظيفتها المنهجية في تحديد المحال الرؤيوي للباحث في دراســــة الظـــــاهر الطبيعية والإنسانية، وتتضح صلتها بالمعرفة العلمية من خلال امتدادها الخفي في صياغة

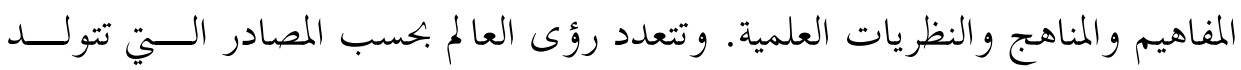

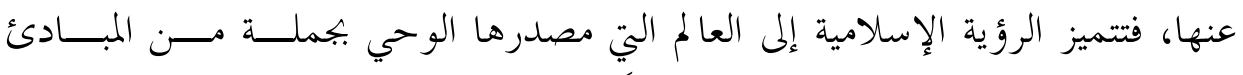

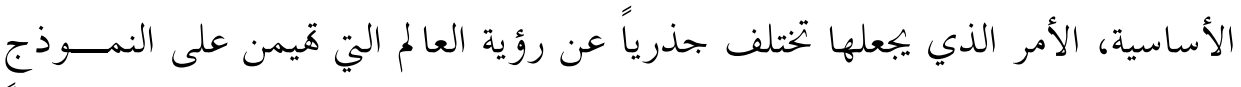

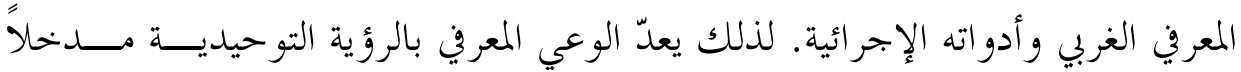

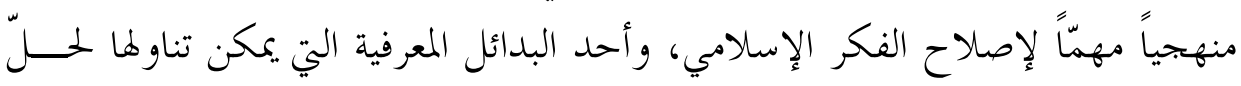
الأزمة الإبستيمولوجية التي تعاني منها المعرفة الوضعية.

عبّر محمد إقبال عن رؤية العالم بمفهوم روح القرآن في كتابه "بحديد التفكير الديني

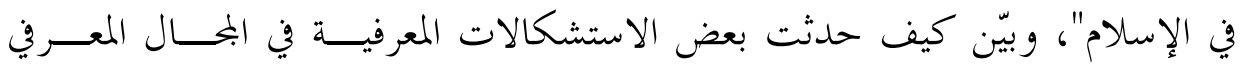

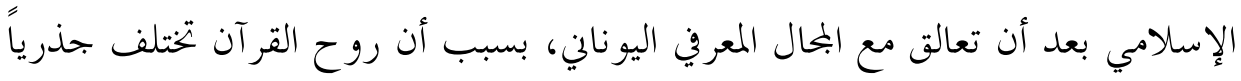

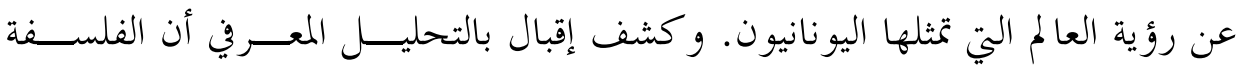

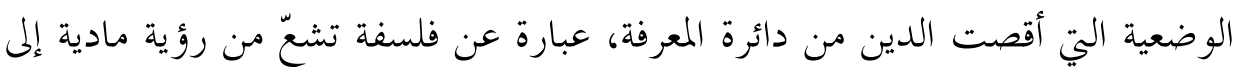

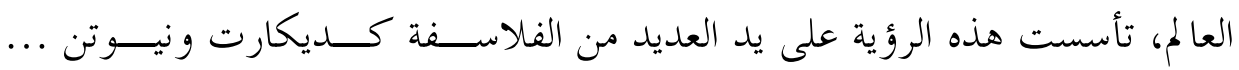

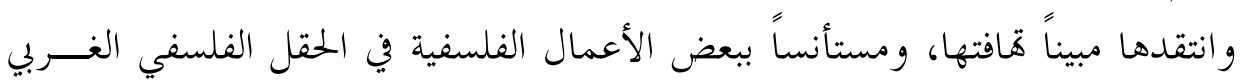
ذاته، كأعمال وايتهيد في الميتافيزيقا، وأبحاث بيرجسون في الزمان و والديمومة.

و سعى إقبال إلى دحض الشرط المنهجي الذي وضعته الفلسفات الغربيــة عـــن

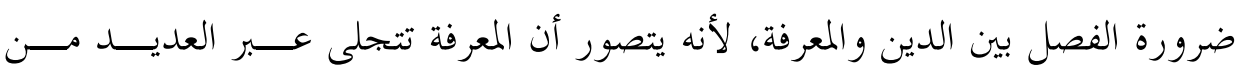

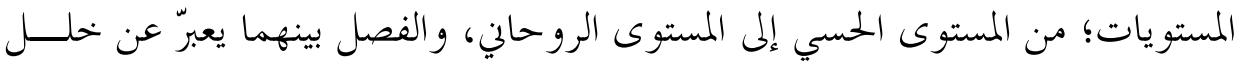

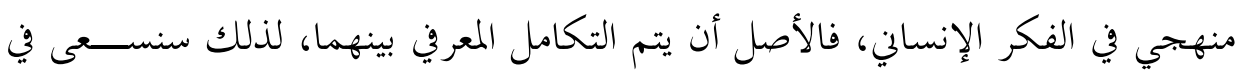

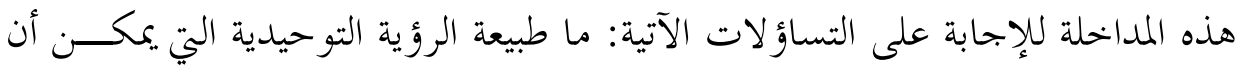


نستنبطها من نص محمد إقبال؟ و كيف امتدت الرؤية التوحيدية عند محمـــد إقبـــال في نظرته للمعرفة وأدو اها ومصادرها؟ وما هي محددات التكامل المعرفي عند محمد إقبال؟

\section{أولاً: مفهوم الرؤية التوحيدية عند محمد إقبال}

نستنبط مفهوم رؤية العالم عند إقبال في كتابه "بحديد التفكير الديني في الإسلام"،

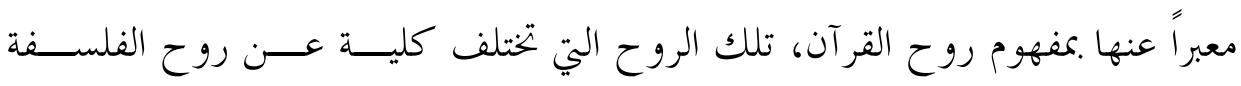
اليونانية، "فلقد كانت الفلسفة اليونانية قوة ثقافية كبرى في تاريخ الإسلام، ومع ذلك ذلك لو أمعنا في النظر في القرآن وفي مختلف مدارس المتكلمين التي ظهرت تحت تأثير الفكر وناس

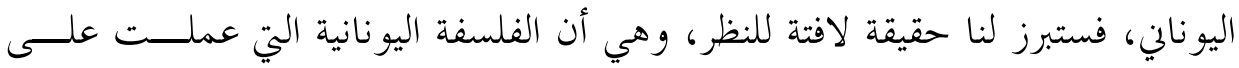

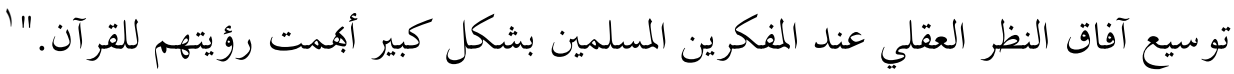
رأى اليونانيون أن الفلسفة بدأت عند السفسطائيين "تتجه نخو الإنسان، و انصرف سقراط يحاول معرفة حقيقته...فليس سوى النفس الإنسانية جديرة بالبحث، ولا خير

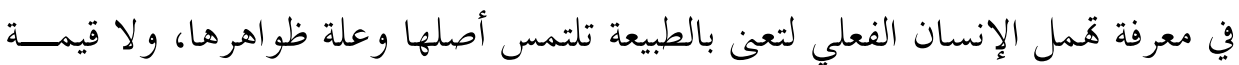

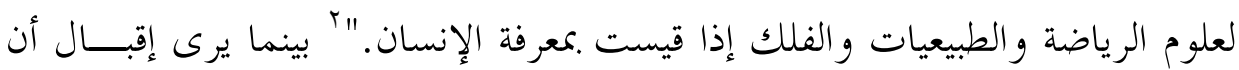
روح القرآن تقع على النقيض من الدعوة السقراطية للتأمل في ذات الإنسان، فالقرآن

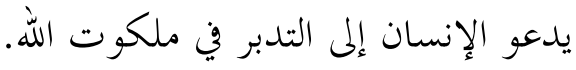

أما المبدأ الثاني الذي نميز فيه بين روح الفلسفة اليونانية وروح القرآن؛ فيتمثل في

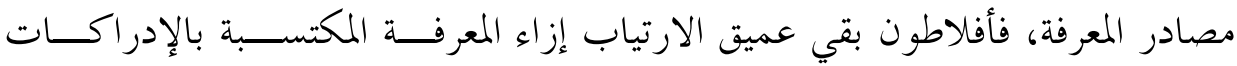

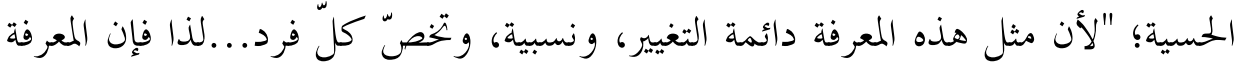

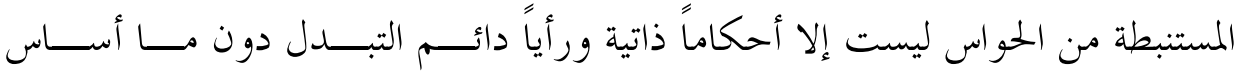

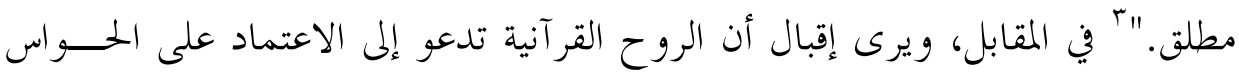
' إقبال، محمد. تجديد الفكر الديني في الإسلام، ترجمة: محمد يوسف عدس، القــاهرة: دار الكتـــاب المصــري،

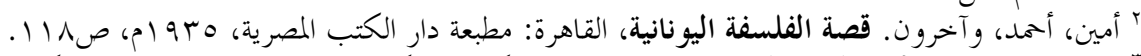

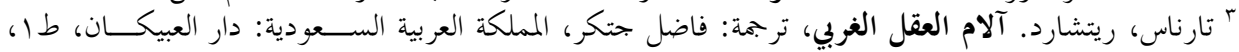


لمعرفة العالم، فالعديد من الآيات التي تدعو الإنسان إلى استخدام حواسّـــهـ ليتــــبر في

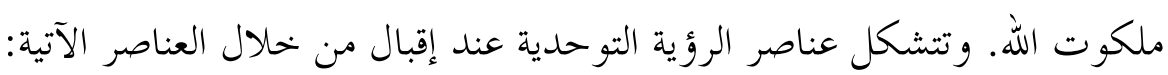

\section{ا ـ الألوهية في الرؤية التوحيدية:}

في البدء؛ أبطل محمد إقبال الحجج التي صاغها المدرسيون في إثبـــات و جــــود الله

بالآتي:

أ. إبطال الدليل الكولي: يقوم هذا الدليل على فكرة أن الكون: "معلول متنـــاه،

وأن هذا العالميمرّ في سلسلة من أحداث متعاقبة، يرتبط بعضها ارتباط العلل .معلو لاهّا

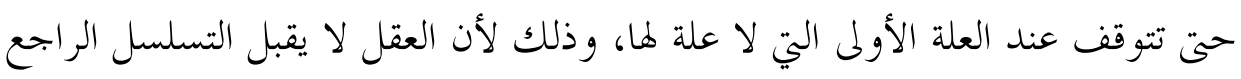

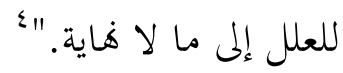

و يقوم بطلان هذا الدليل على نقض منطقي لفكرة الانتقـــال مــنـ المتنـــاهي إلى إلى

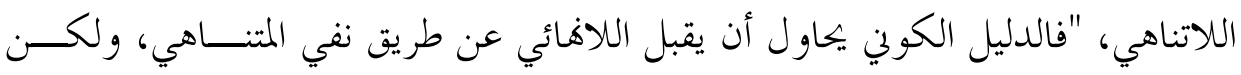

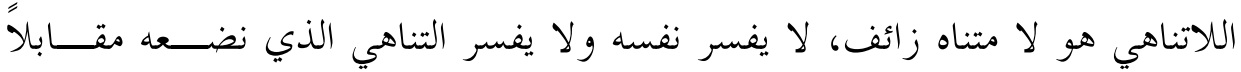
اللامتناهي." الماهي"

ب. إبطال الدليل الغائي: يرى إقبال أن هذا الدليل أكثر قافتـــاً مــنـ الــدليل

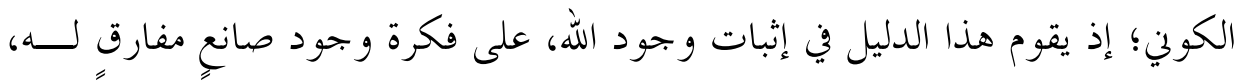

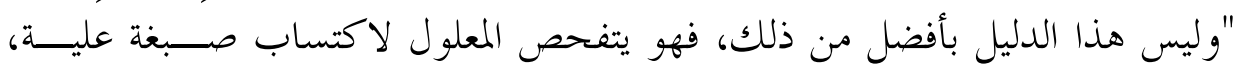
و يستنتج من أثنار البصيرة والقصد والتوافق في الطبيعة وجود كائن وائن واعِ بذاته لا هائي

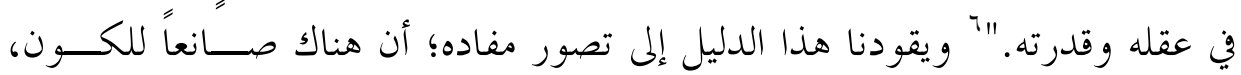

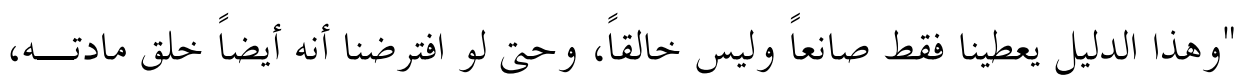

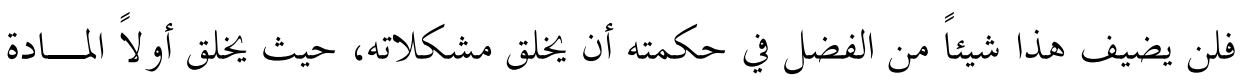

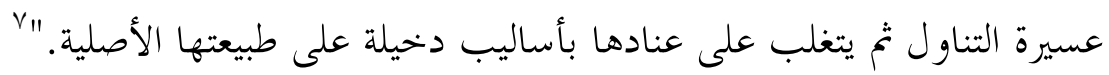

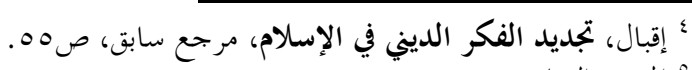

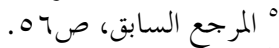

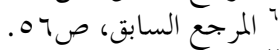

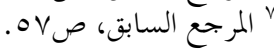




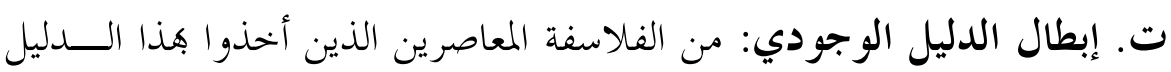

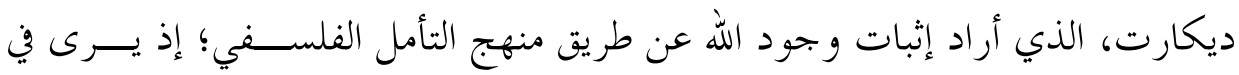

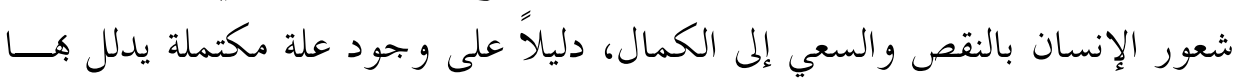

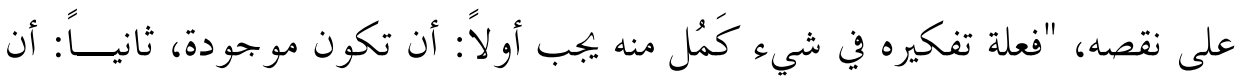

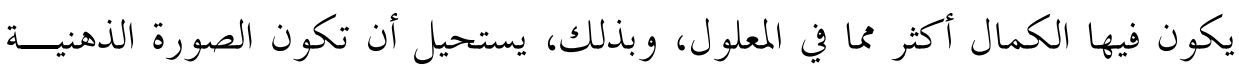

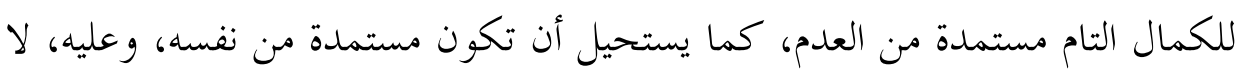

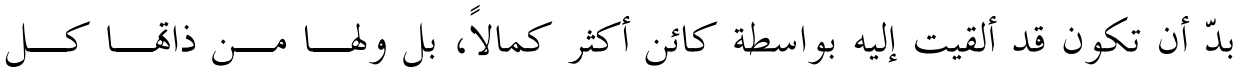

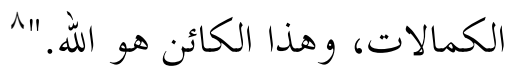

ويقع بطلان هذا الدليل من وجهة نظر إقبال من جهة عدم التطابق بين التصــور

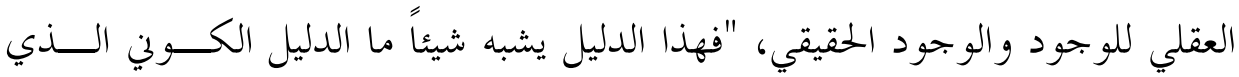

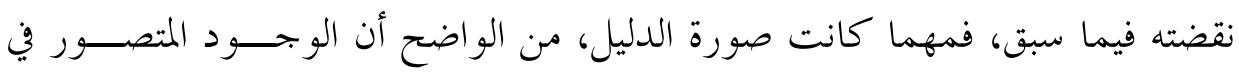

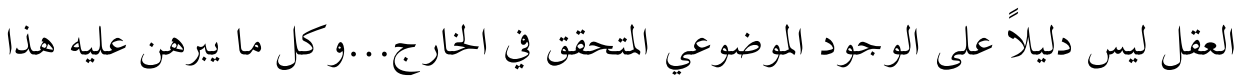

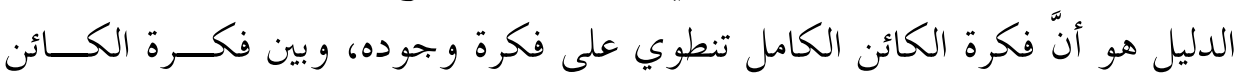

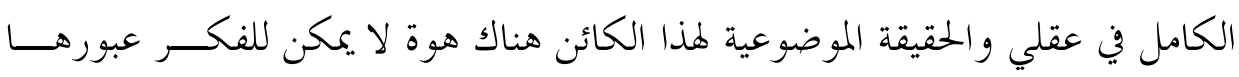

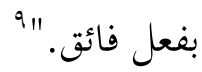

بعد هذا النقد الفلسفي للأدلة التي ساقها الفلاسفة على وجود الله، ينتقل إقبــال

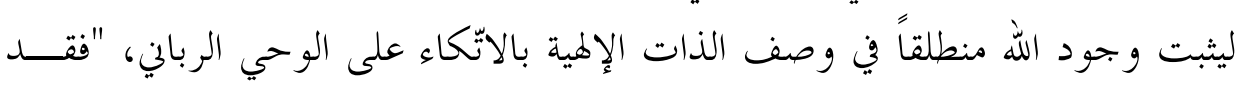

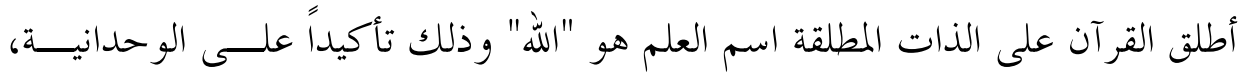

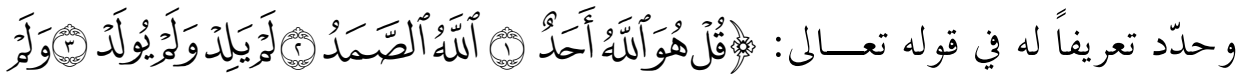

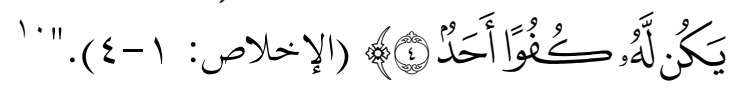

ويختلف التوحيد كمقولة معرفية عند إقبال عن التوحيد الــــي عرفتــهـ الفــــق

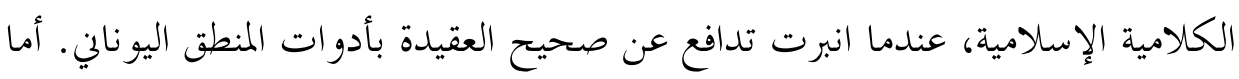

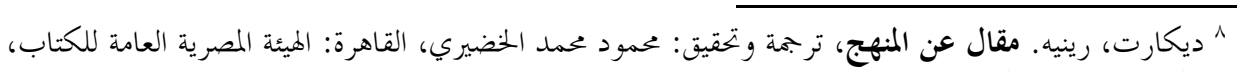

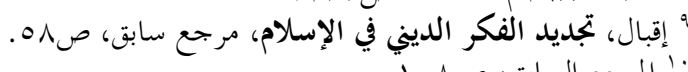


ما قصده إقبال؛ فهو إعادة النظر في التوحيد كمقولة تتو الد عنها أفعال إنسانية، ولعلنا نستأنس ببعض أبياته الشعرية لفهم مقصوده؛ "فالتوحيد قوة في الحياة على الأرض قبل إلى فيال

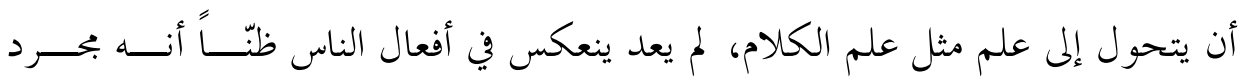
عقائد، التوحيد كالسيف في غمده، التوحيد النظري دون العملي بجرد لغو." "' وهنا،

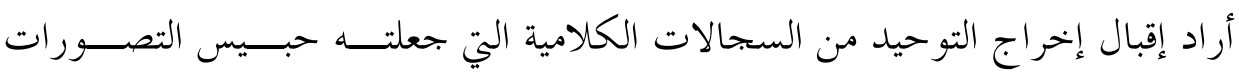
الاعتقادية.

ويستأنف محمد إقبال توضيح فكرته؛ بأنَّ واحدية الذات الإلهية، تقع على النقيض

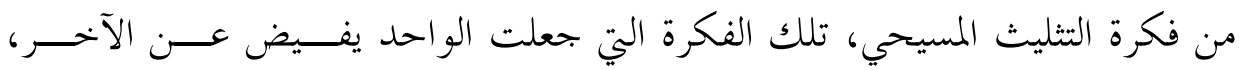

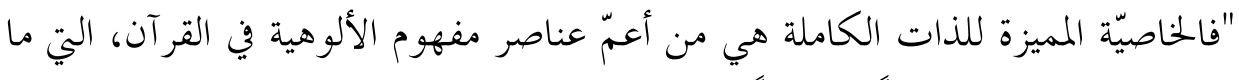

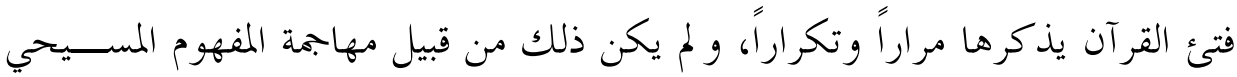

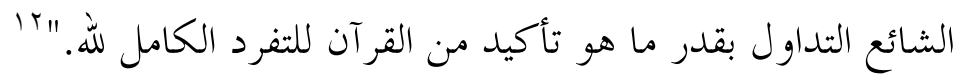

و ينفي إقبال نفياً قاطعاً أن تكون الوحدانية الإلهية دالة على التناهي، كما تصوره الفلسفات المادية؛ التي ينبع خطؤها من تصورها اللاهائي من زاوية عقلية، "فــالعقول

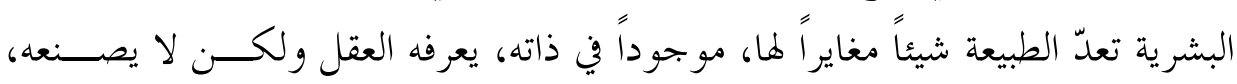

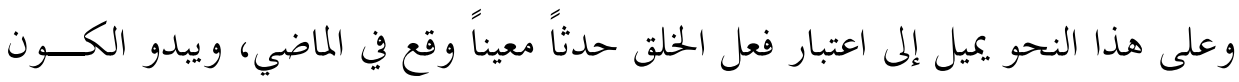

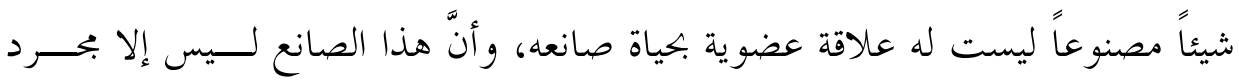

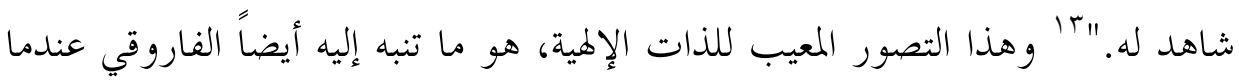

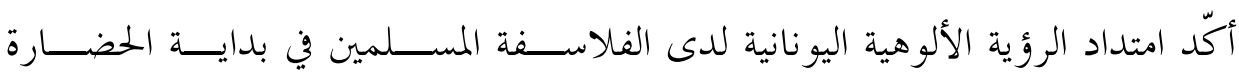

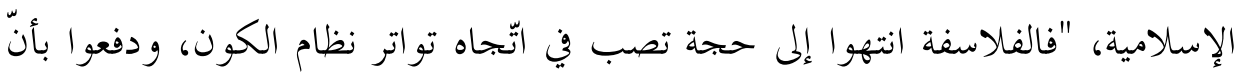

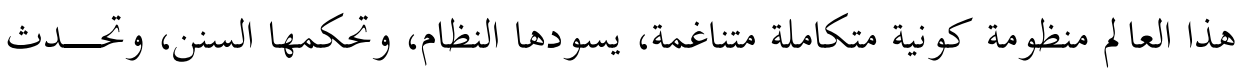

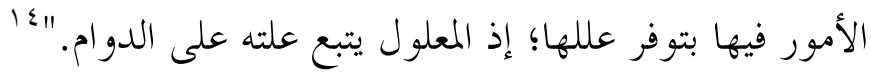

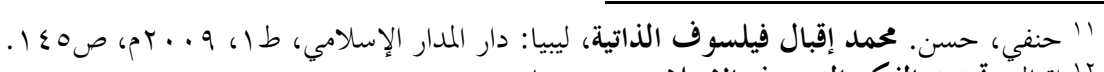

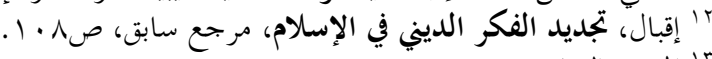

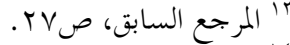

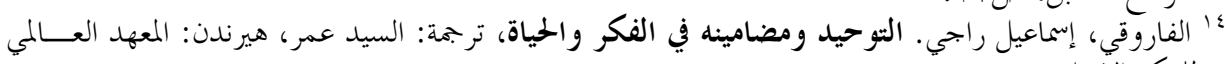


بينما تصد علماء الدين للفلسفة اليونانية، وقدموا رؤية مغايرة لهذه الرؤيسـة الــتي

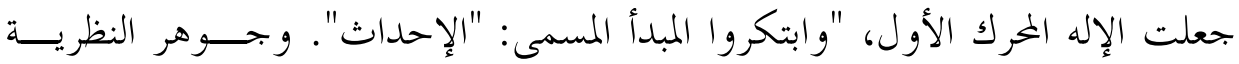

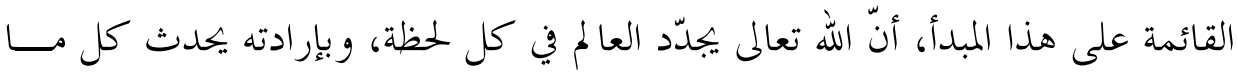
يحدث فيه، والمتحكم في نظام العالم، وبذلك، ليس هو السببية المحضة، بل الثقة بأنَّ الله تعالى، يهلى عباده إلى معرفة الأثر الصحيح الذي سيترتب على سببه الصحيح، بما أنّه سبحانه عادل وعلى صر اط مستقيم، ولا يرضى لعباده الضلالة. ولبّ هذا التصور هو

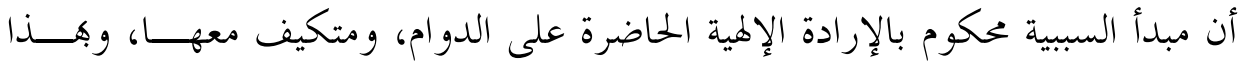
التناول كانت لرجال الدين الحجة البالغة على الفلاسفة."

و تتمثل السمة الأساسية للتوحيد في تجاوز الفكرة التقابليـــة: (الكـــــن، الله)؛ إذ إذ

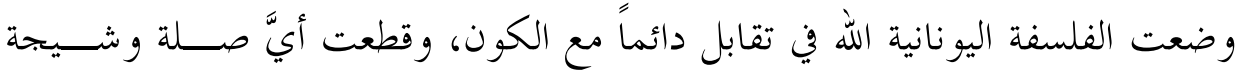
بينهما، وفي الفلسفة المعاصرة تم الانتقال من التقابلية البرانية إلى التقابليــة الجوانيـــة، فأصبحت هناك ثنائية: النفس والجسد، الوعي واللاوعي... بينما التوحيد لا يضع الله في مقابل الكون، "فمن وجهة نظر الإلهية ليس هناك خلق مععن حادث معين "قبل" وله

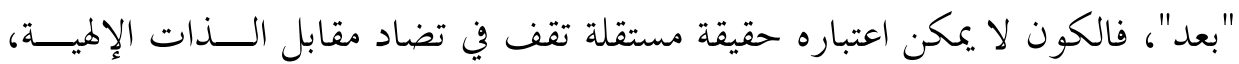

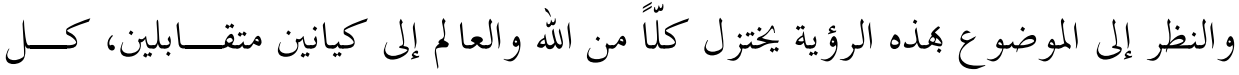

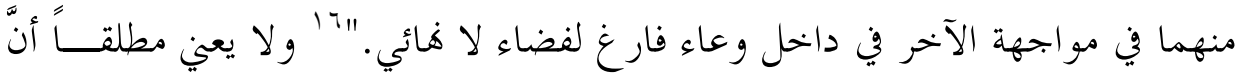

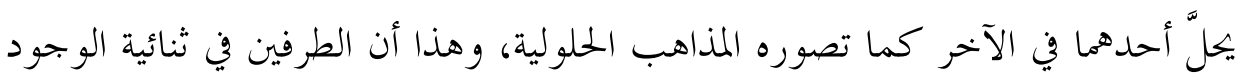
التوحيدية، طرفان بعيدان في الحقيقية الذاتية، حيث يتصف الله تعالى بالكمال المطلق،

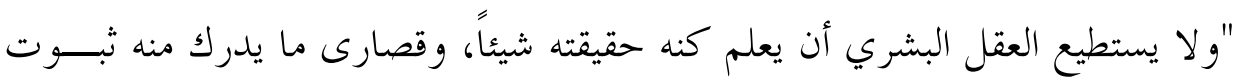
صفات الكمال له، في حين يتصف العالم بصفات النّقص والدون إزاءه، وهو ذو طبيعة

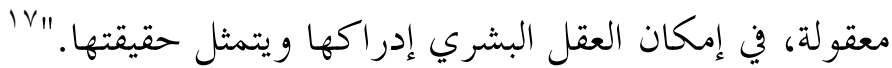

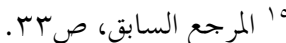

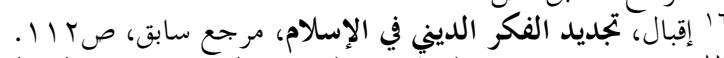

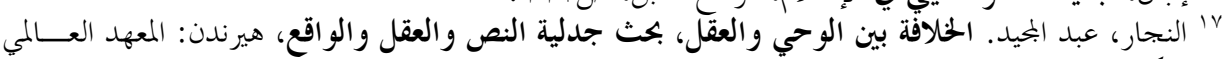




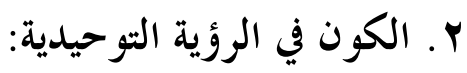

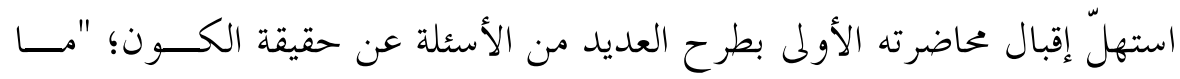

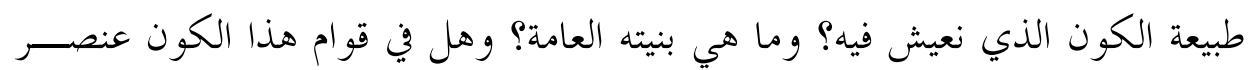

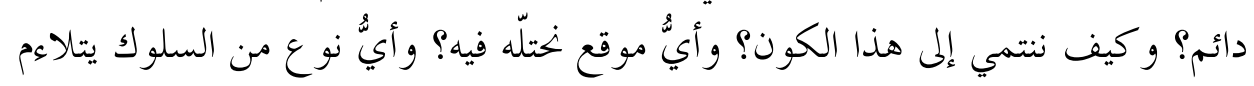

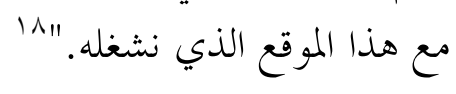

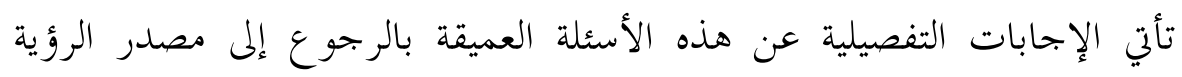

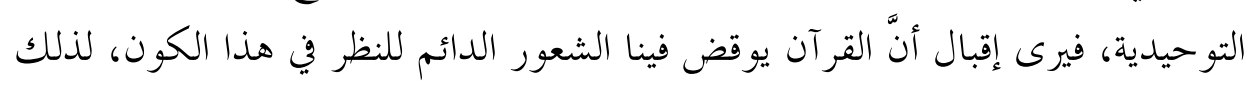

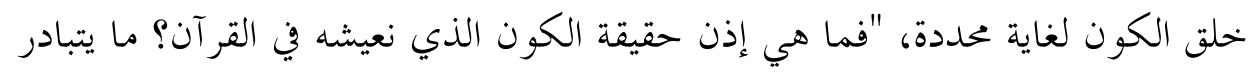

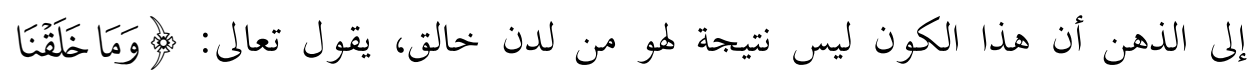

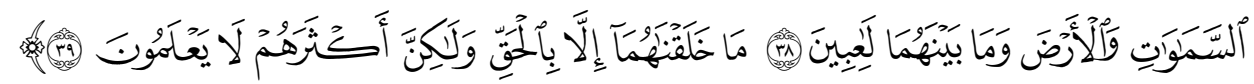

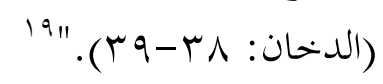

تعطي فكرة الغائية في خلق الكون، كثيراً من المعاني الروحية التي تضع الإنســان

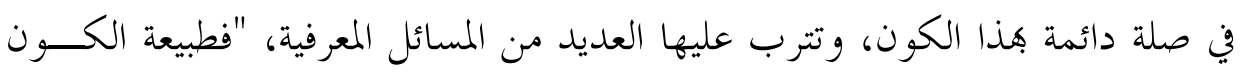

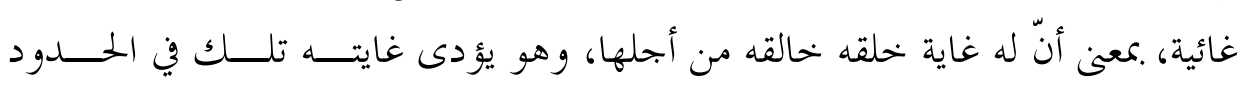

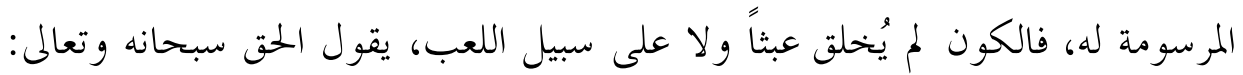

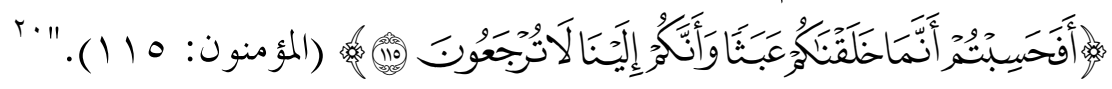

ولا يجب الأخذ .بمفهوم الانفصال بين الذات الإلهية والكون، كأن نتصــــور أنّ الله

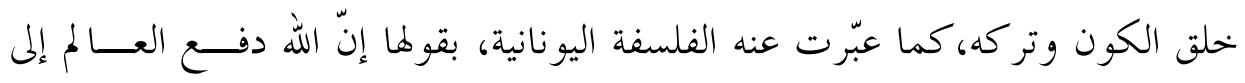

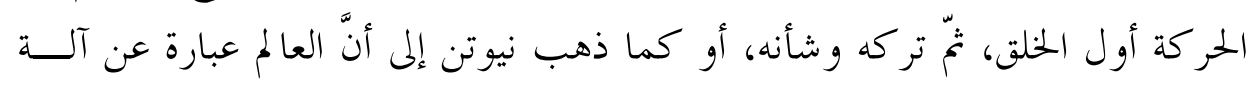

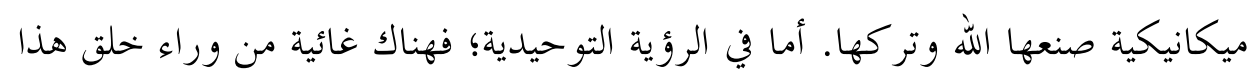

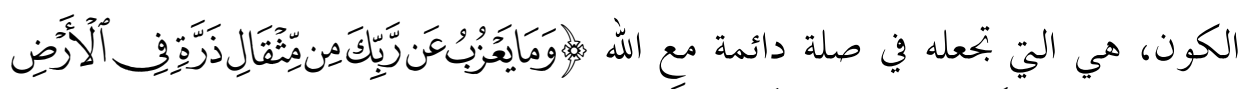

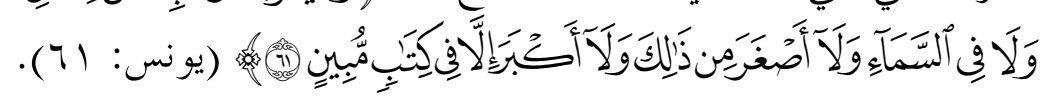

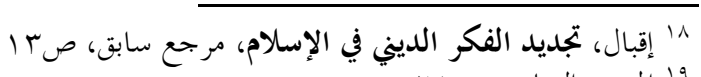

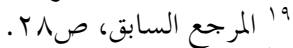

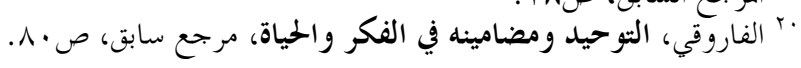


و لا يقبع الكون من منظور إقبال ساكناً جامداً، "فالكون قد خلق على نحو يجعله

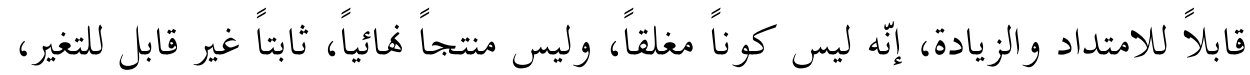

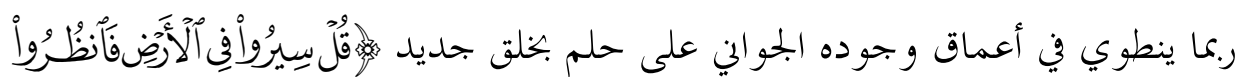

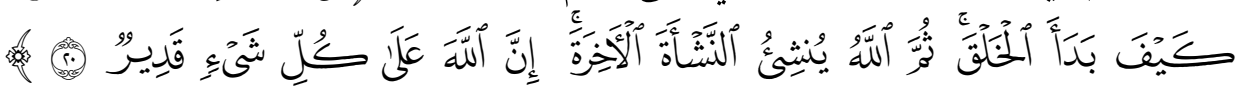

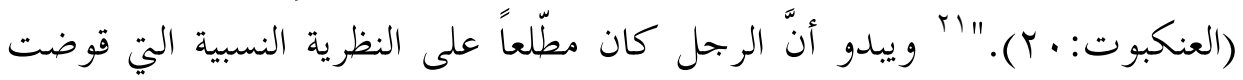

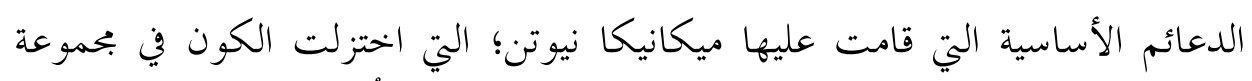

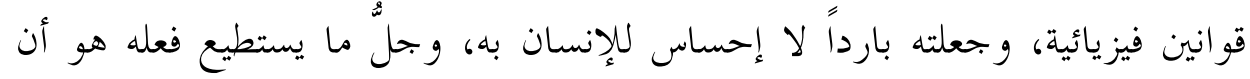
يكتشف قوانينه للسيطرة عليه و اخضاعه لإرادته، "فبعد الثورة التي أحدثتها النسبية

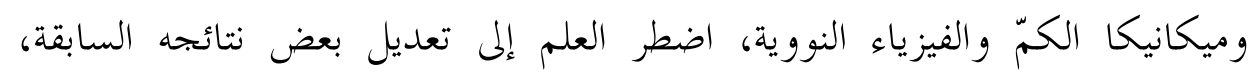

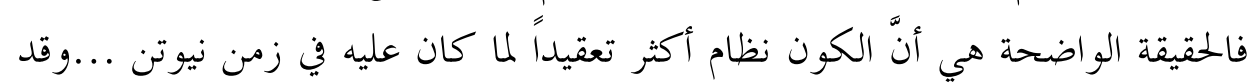
انعكس هذا التغير على وضع متفتح الذهن بتحاه الفلسفات المثالية، وعلى مدى ثلى ثلاثة

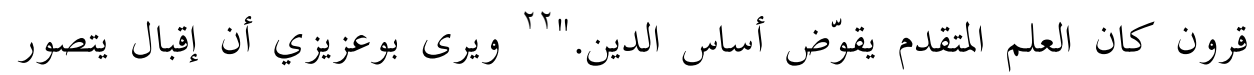

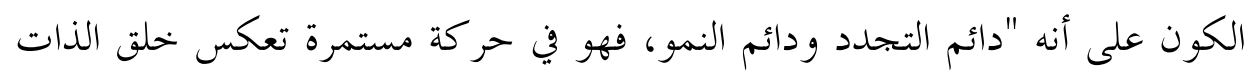

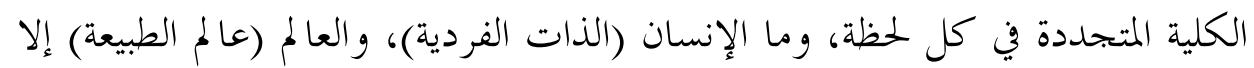
مظهر من مظاهر التجلي لتلك الذات الكلية (الله)، فالصلة بين هذه الذوات صلة لا لا تنفصسم.

و هذا الامتداد في الكون لا يتمّ إلا برحمة الله، "فقد بحلت رحمة الله غير المتناهية في

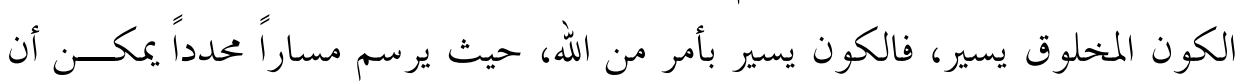
يتحول الكون عن طريقه إلى وحدة عضوية، فالمخلوقات جميعها، بما في ذلك الإنسان

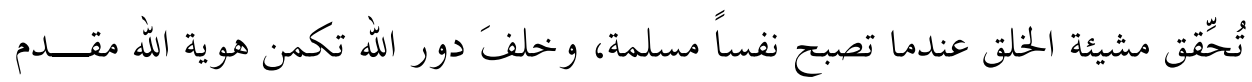

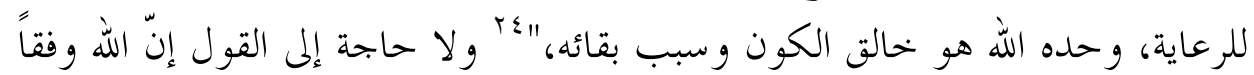

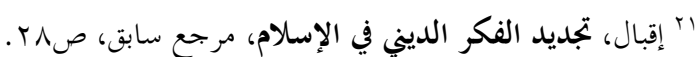

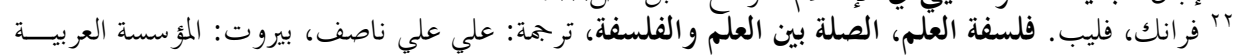

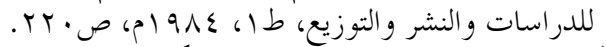

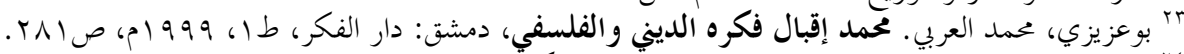

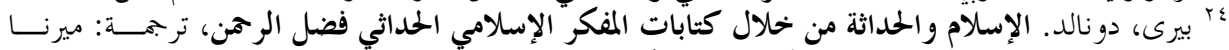

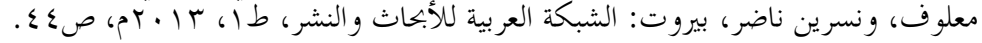




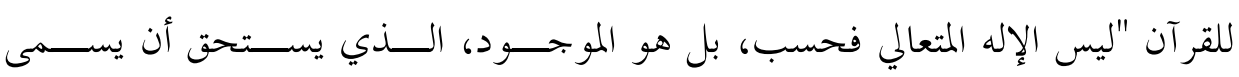

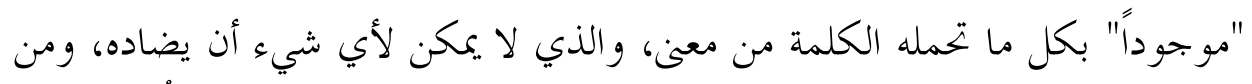

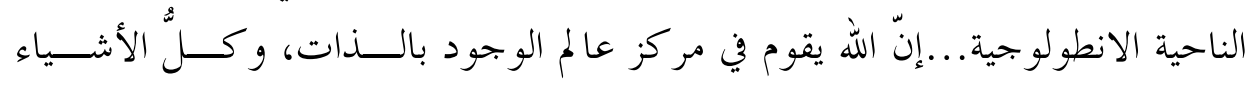

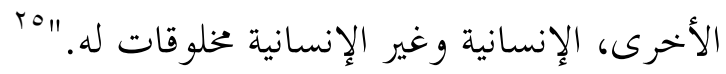

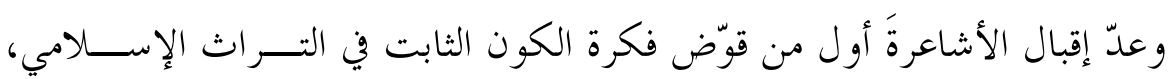

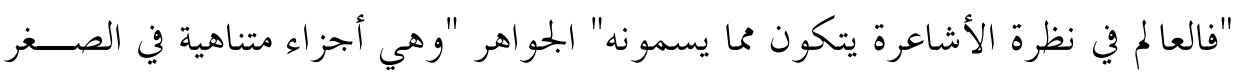

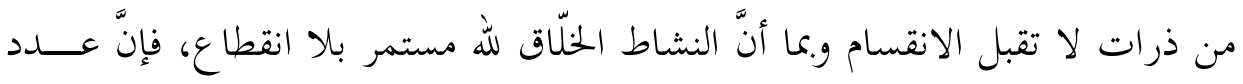

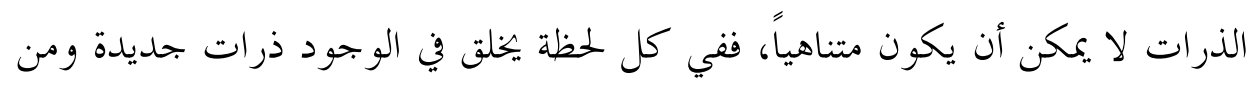

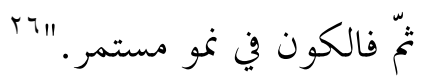

\section{r. الإنسان في الؤية التوحيدية:}

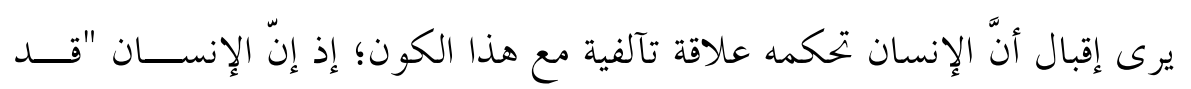

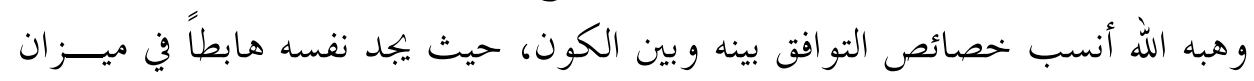

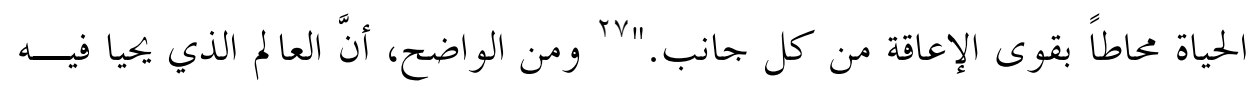

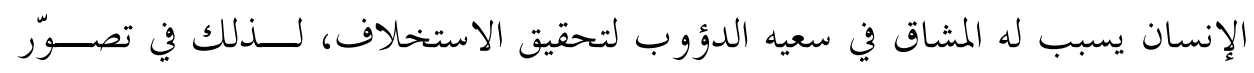

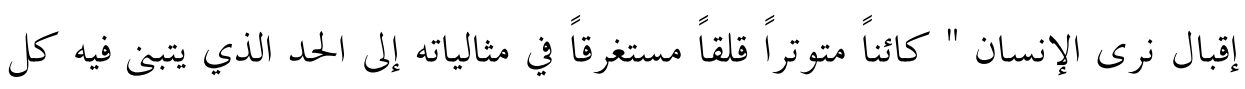

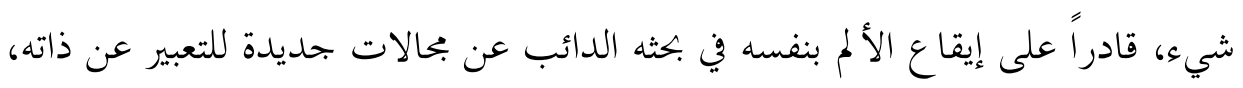

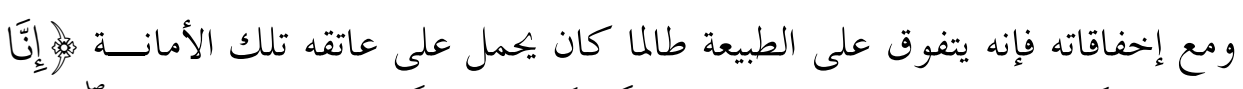

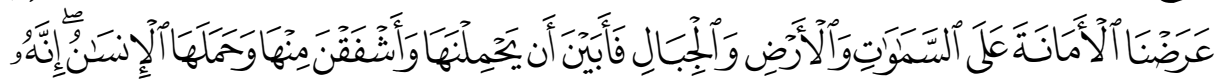

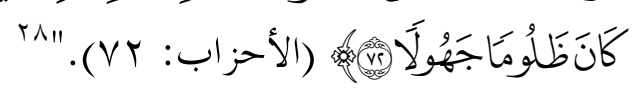

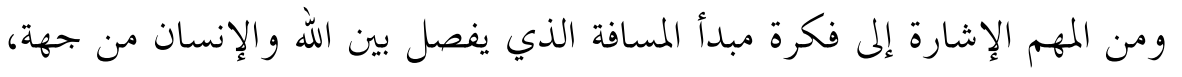

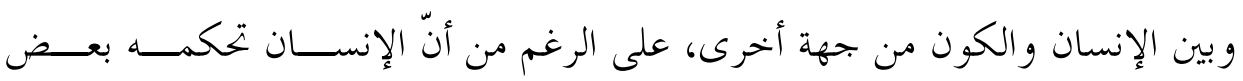

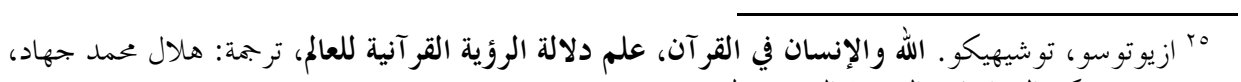

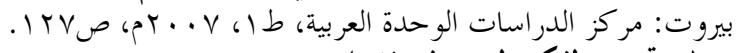

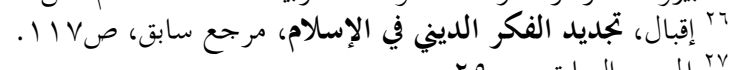

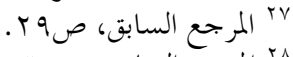

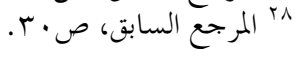




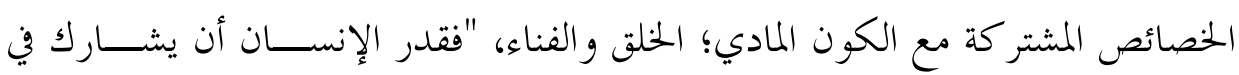

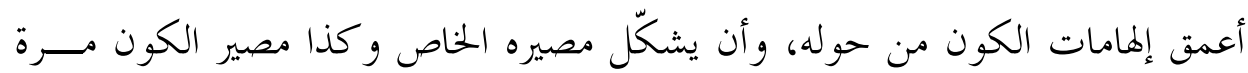

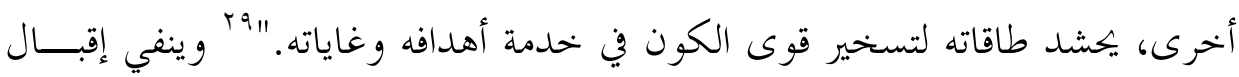

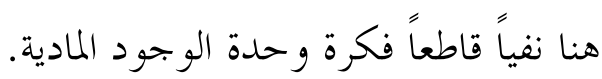

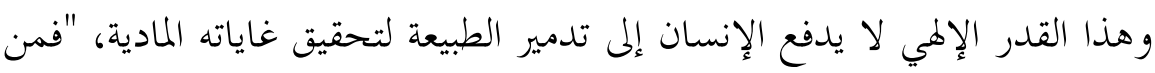

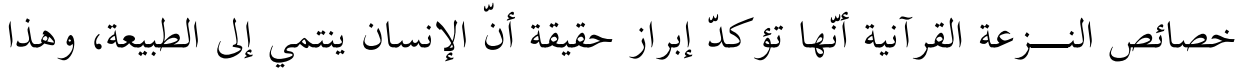

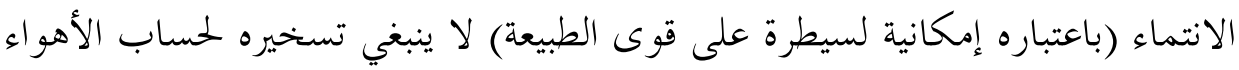

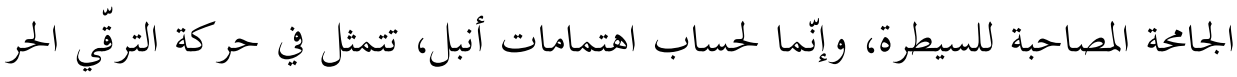

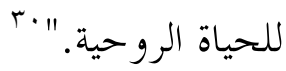

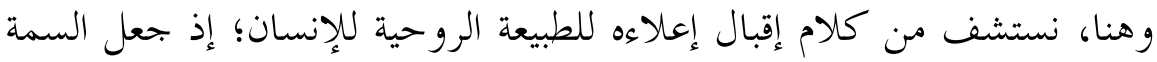

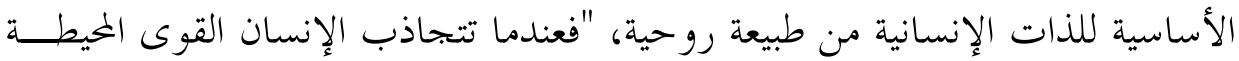

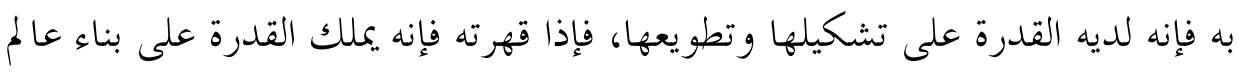

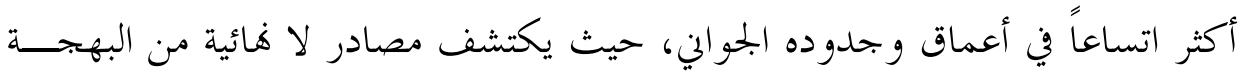

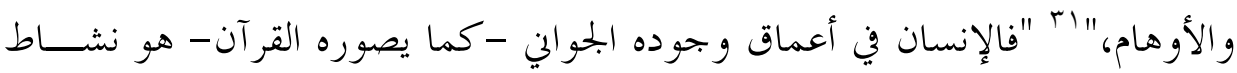

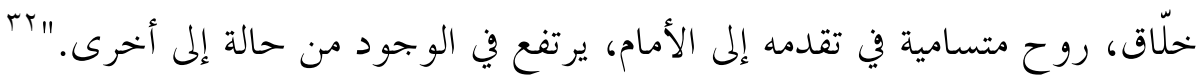
تقع هذه الرؤية الروحانية للإنسان على الطرف النقيض مما ذهبت إليه الفلسفات

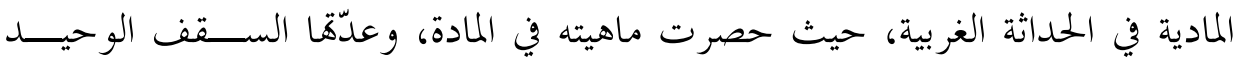

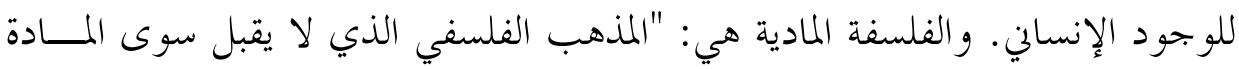

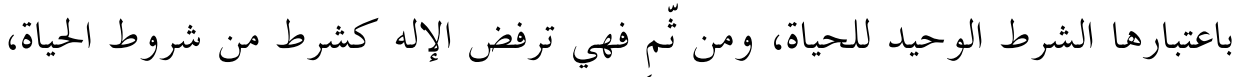

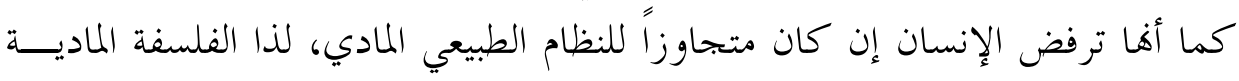

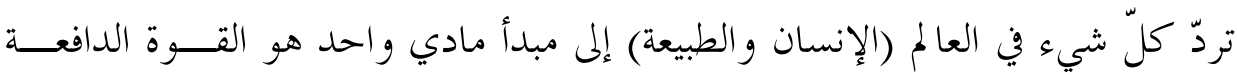

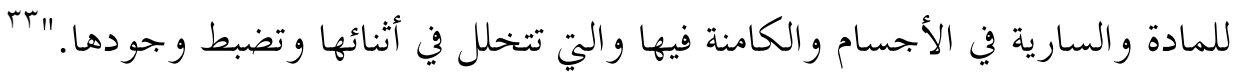

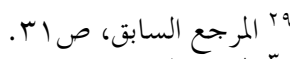

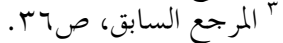

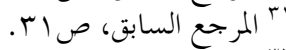

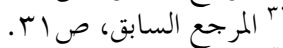
TrT المسيري، عبد الوهاب. الفلسفة المادية وتفكيك الإنسان، دمشق: دار الفكر، طا، ب .. Tم، صVا. 


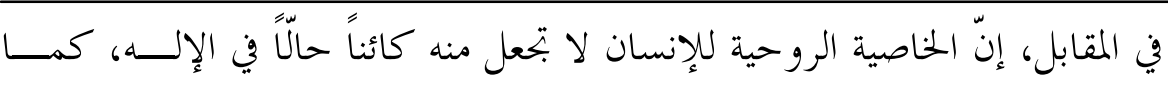

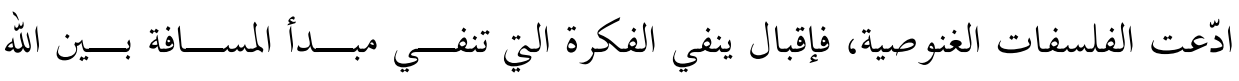
و الإنسان، "فإقبال صوفي أب عن جدّ، لكنه يرفض و حدة الوجود لنتائجها الســـلبية على حياة المسلمين، و لا رهبانية في الإسلام، و إنّما الرهبانية في المسيحية وفي التصوّف الإلير اني.

كما لا يقطع الإنسان أيّ صلة بخالقه، فأتت العبادات و الشعائر لتقوية هذا الصلة بين الإنسان وربه، "فالصالة سواء كانت فردية أو هماعية هي تعــبير عــن أشـــواق

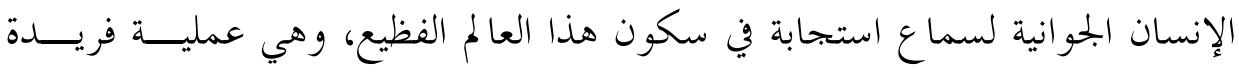
لاستكشاف تؤ كد فيها الذات الباحثة و جودها في اللحظة نفسها التي تنكر فيها هـــــهـ

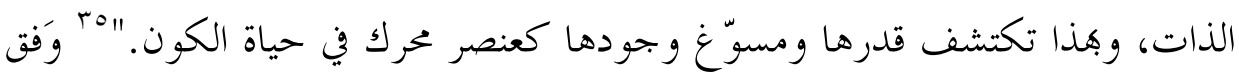

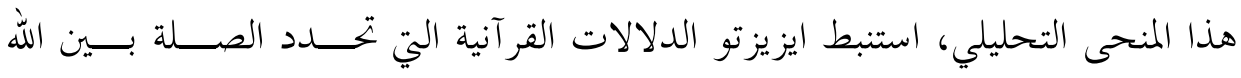
و الإنسان في القرآن الكريم في:

- العلاققة الانطولو جية: بين الله بوصفه المصدر الجوهوي للوجـــود الإنســـاني،

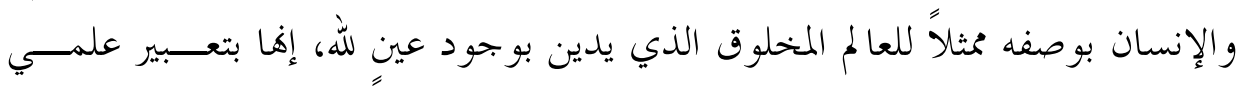
ديني، علاقة (الخالق/المخلوق) بين الله و الإنسان. - العلاقة التو اصلية: يدخل الله والإنسان في علاقة تبادلية وحميمة كل منهما مع

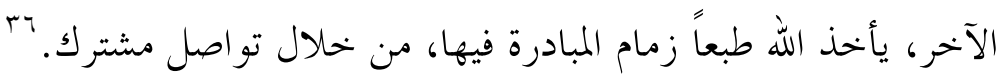
ـ علاقة الرب/العبد: تستلزم هذه العلاقة من جهة الله بوصفه "الربـ" المغـــــيم كلّها المتعلقة بجالالته وعظمته وقلدرته المطلقة....6 بينما تستلزم من جهة الإنسان كعبد له، بحموعة من المفاهيم التي تتضمن الخضوع و الطاعة المطلقة وغير ذلك من الخصائص التي ينبغي عادة أن تتوفر في العبد.

ـ العلاققة الأخلاقية: هذه العلاقة تقوم على ذلك التغاير الأساسي جـــــاً بــــن الوجهين المختلفين اللذين يمكن تمييزها في مغهوم "الله" عينه : إله الخير و المغفرة والرحمة

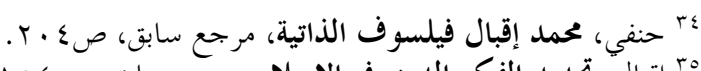

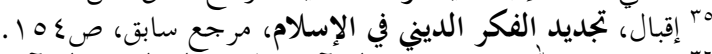

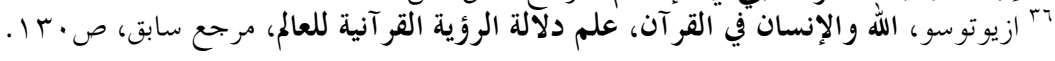


و الكرم غير المحدود من جهة، وإله العقاب و العدالة الصارمة، من جهة أخهـرى، وتمـــة نظير من ذلك في جانب الإنسان يتمثل في التغاير الأساسي بين "الشكر" من جهـــة،

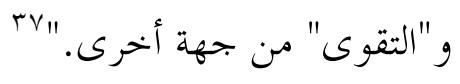

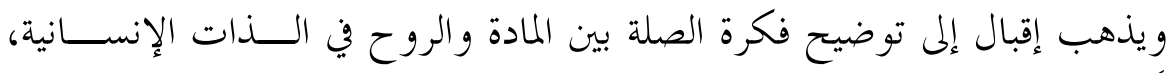

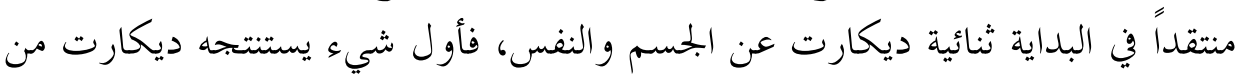

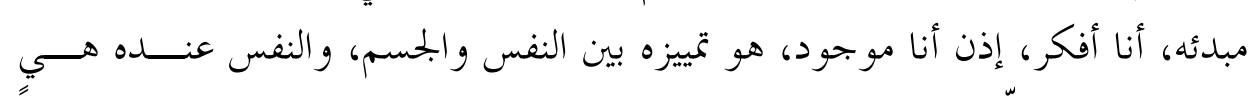

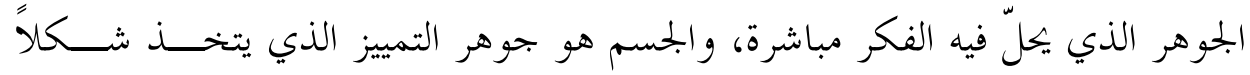

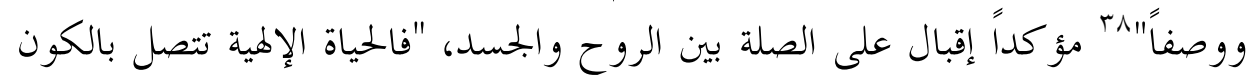

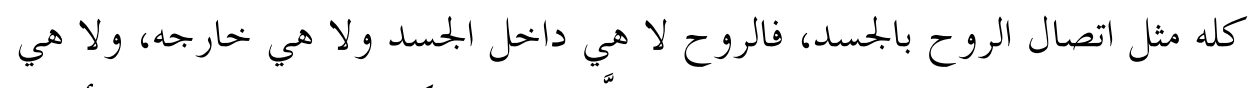

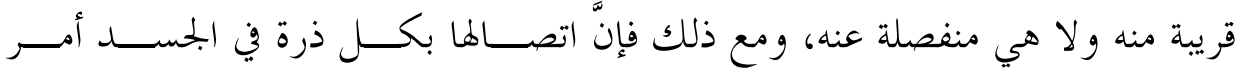

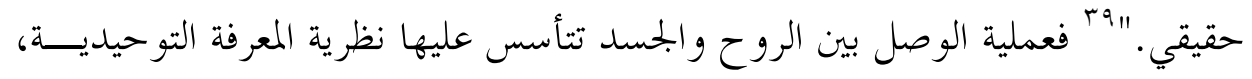

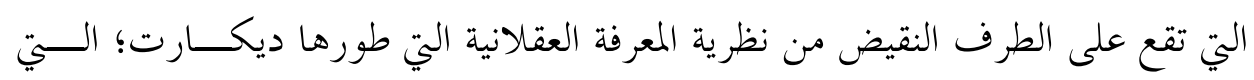
تنفي البعد الروحي في المعرفة الإنسانية.

ثانياً: في نظرية المعرفة، ومفهوم التكامل المعرفي عند محمد إقبال ا ـ في نظرية المعرفة عند محمد إقبال:

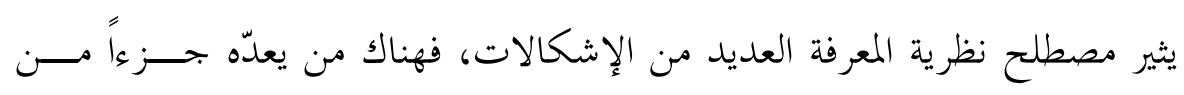
فلسفة العلوم، ويذهب بعضهم الآخر لتصنيفه ضمن تاريخ العلوم، لكن لا يختلف اثنان

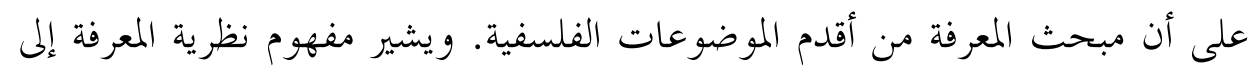

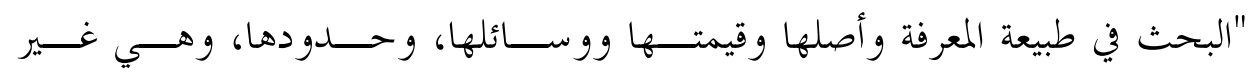

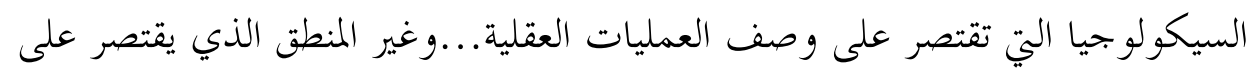

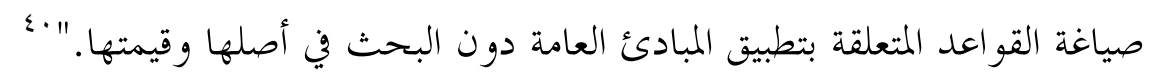
(rv

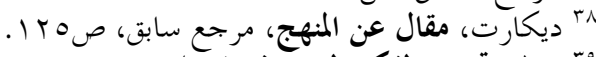

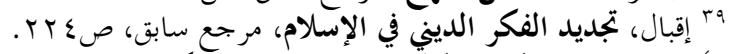

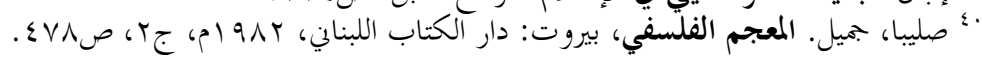


من هذا المنطلق، نستخدم مصطلح نظرية المعرفة كمبحث من مباحث الفلســفة،

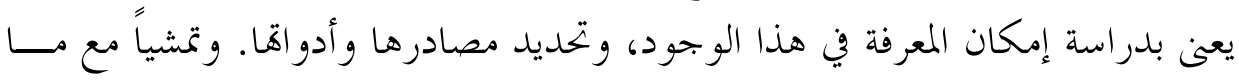
نروم إليه من تحليل لنظرية المعرفة عند محمد إقبال، فإننا نسائل طبيعة المعرفة بين إمكاهانا

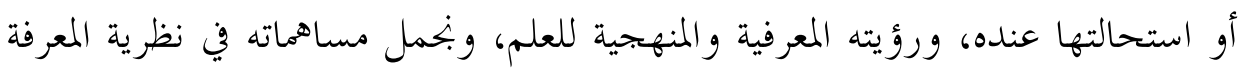
كما يأتي:

\section{أ. نقد نظرية المعرفة عند اليونانيين:}

يميل إقبال في بناء نصّه الفلسفي إلى دحض المقدمات التي تنافي تصوره للقضــايا،

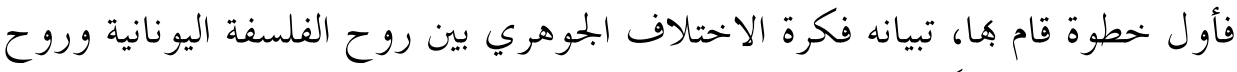

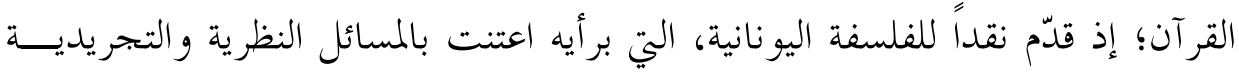

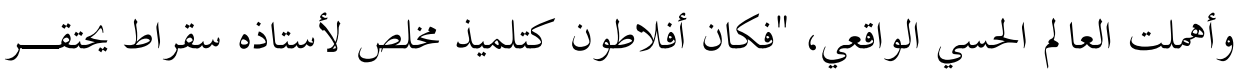

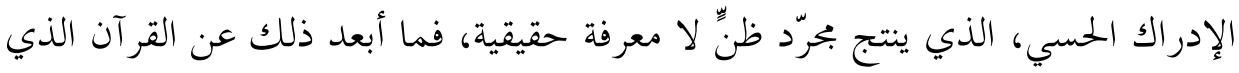

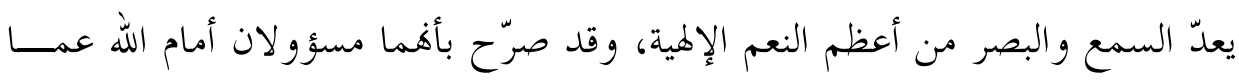

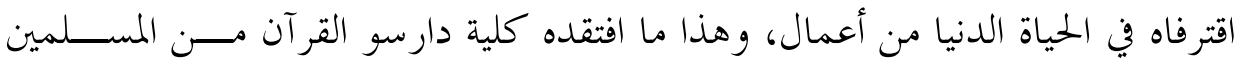

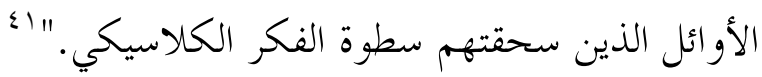

وأدت هيمنة الفكر اليوناني على المسلمين في المائيت السنة الأولى مـــن تــاريخهم

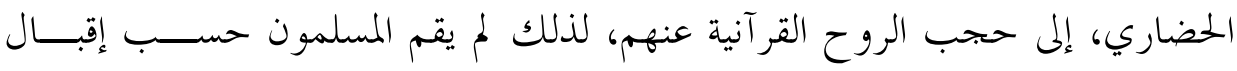

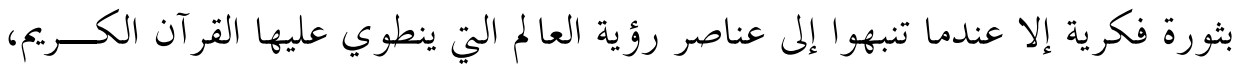

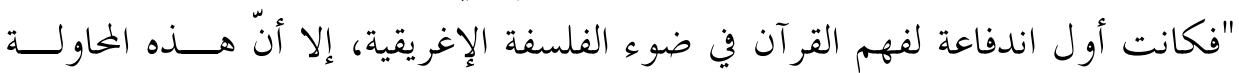

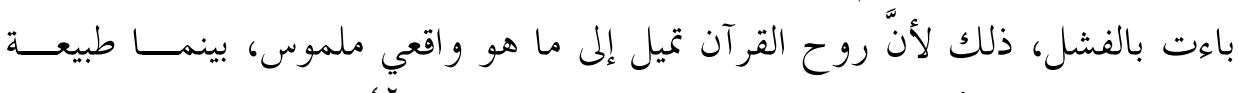

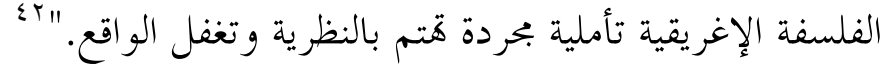

وعدّ إقبال مدرسة الأشاعرة أوّل من قام هذه الثورة العقلية في الفكر الإسلامي،

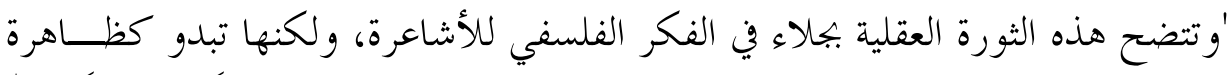

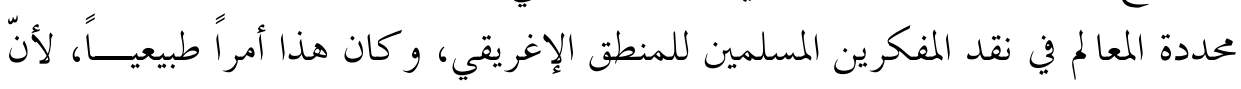




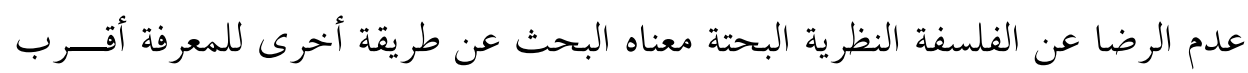

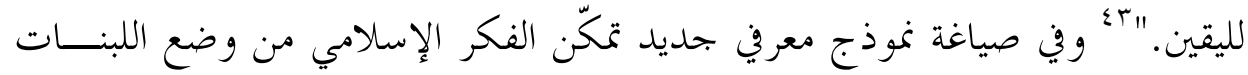

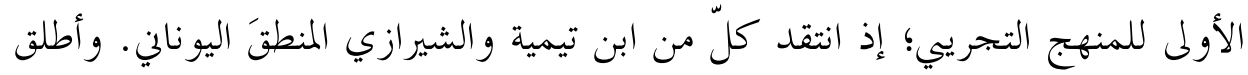

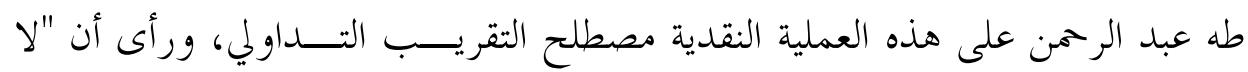

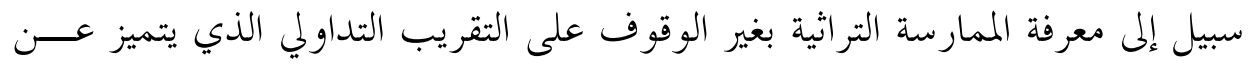

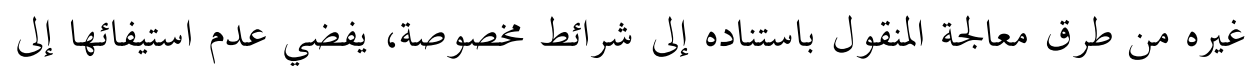

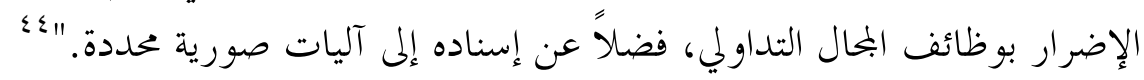

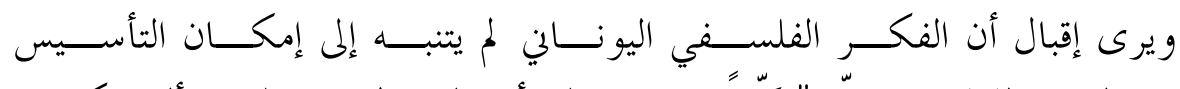

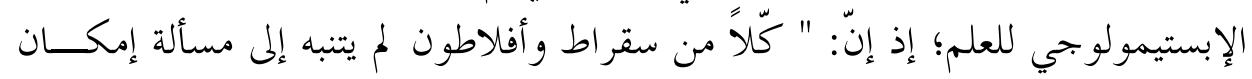

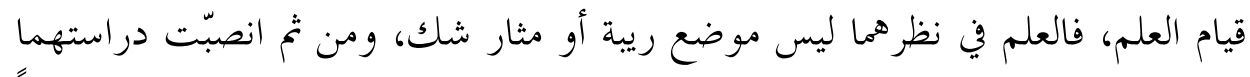

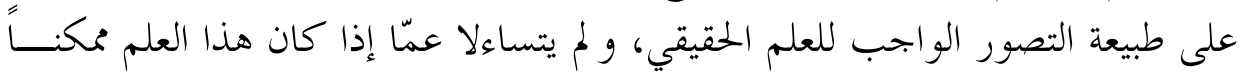

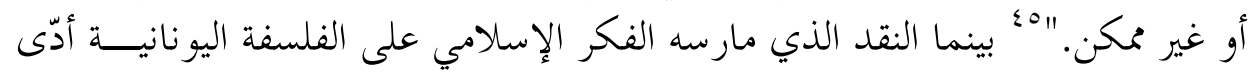

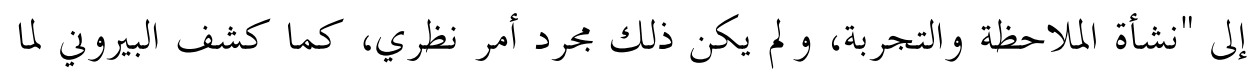

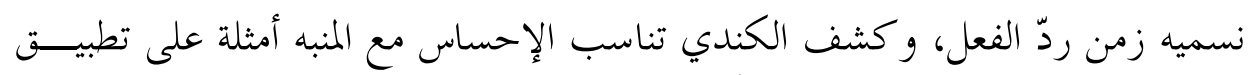

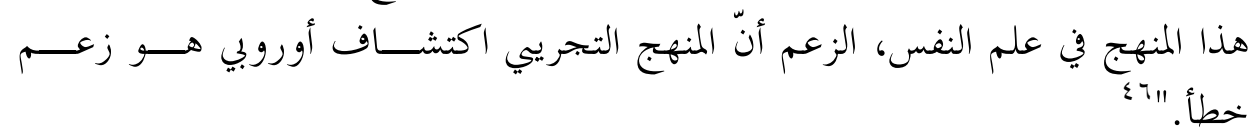

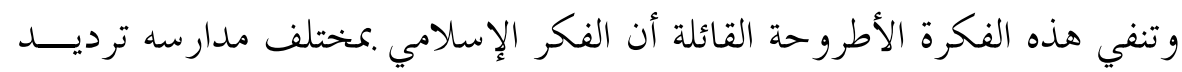

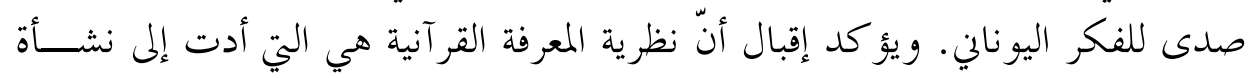

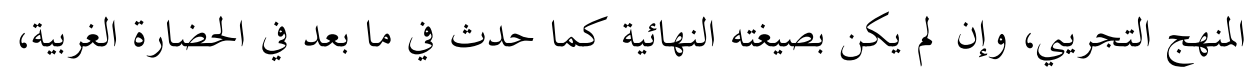

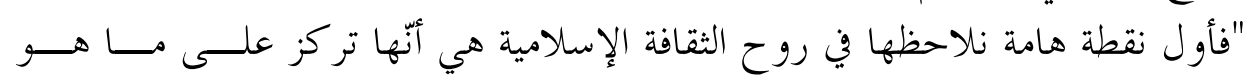

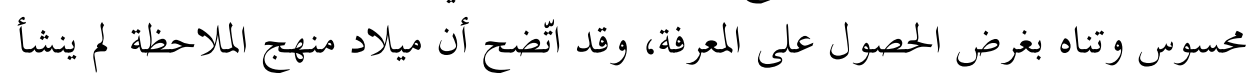

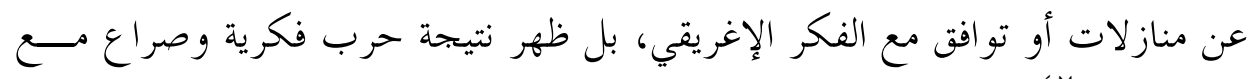

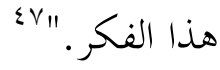

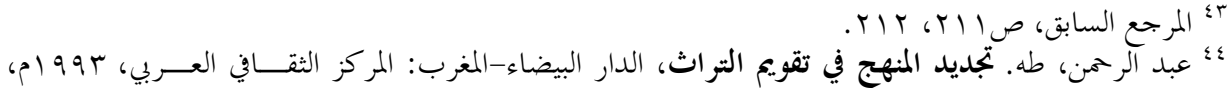

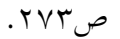

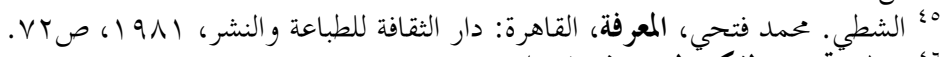

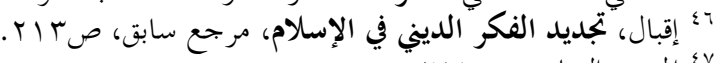




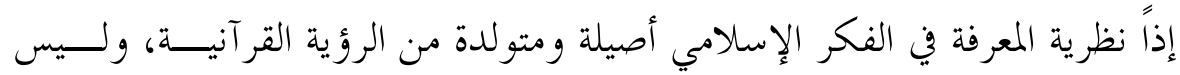
كما ادّعت العديد من الدراسات الاستشراقية أن الفكر الإسلامي لم يقدم للحضـــارة

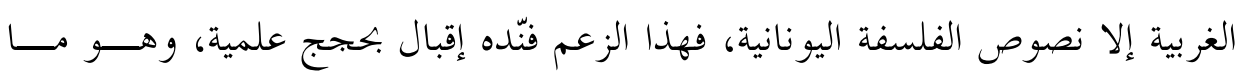
ذهب إليه سيد حسين نصر من أن العلوم في الحضارة الإســلامية حكمتــــها الرؤيسـة التوحيدية، "فوحدة المبدأ الإلهي وما ينتج عنها من و حدة طبيعية، حيث فكرة التوحيد تطغى على ما سو اها وتبقى على مستويات الحضارة الإسلامية هميعها أكثر الأسـسـس

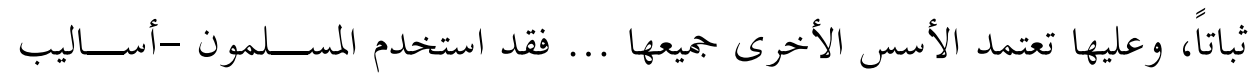
راسية- متعددة لصياغة علوم ترتكز على الفكرة التوحيدية للطبيعة المقتبسة من المصدر

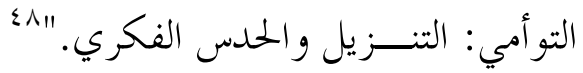

\section{ب. نظرية المعرفة عند محمد إقبال:}

انطلاقًا من الرؤية التوحيدية القائمة على ثنائية(الحالق/المخلوق)، اليتي تلزم عنـــها ثنائية مصادر المعرفة (الوحي و الكون)، ومن البعد الثنائي للإنسان (المادة/الروح)، التي تلزم عنها ثنائية الأدوات(العقل والقلب)، صاغ إقبال مصادر المعرفة وأدواتها. و نبسط الكاملام فيها كمايأني:

\section{- الإدراك الحسي:}

يرى عحمد إقبال أنّ الحسّ من أهـّ مصادر المعرفة، وأول مصدر يستخدمده الإنسان

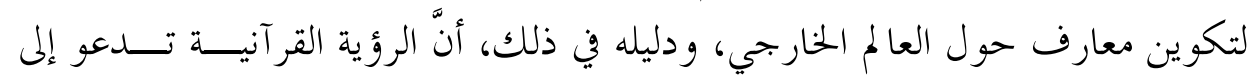
و جوب التأمل في ملكوت الله من ظواهر طبيعية وفلكية، فإذا كانت نظرية المعرفة عند اليونانين قد حقرّت الحسّة فإن إقبال يرى أنّ النحل على ضآلة شأنه هو محل موضع

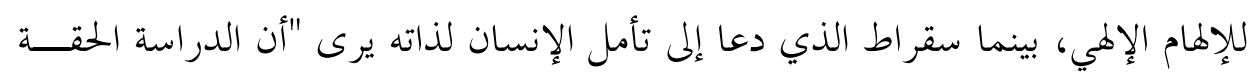
لإإنسان هي دراسة نفسه، وليس عالم النبات و الحشرات و النجوم، وهذه وهذه نظرة مخالفة

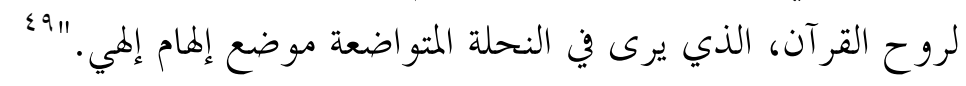
هـ نصر، سيد حسين. مقدمة إلى العقائد الكونية الإسلامية، ترجمة: سيف الدين قصير، دمشق: دار الحوار للنشر 
والمعرفة التي تأتي عن طريق الحواس هي معرفة حقيقية، "فيجب أن تبدأ المعرفة من

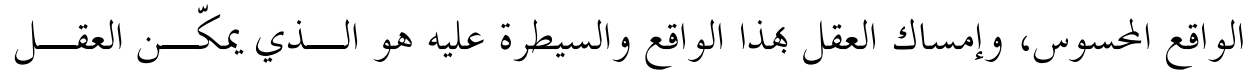

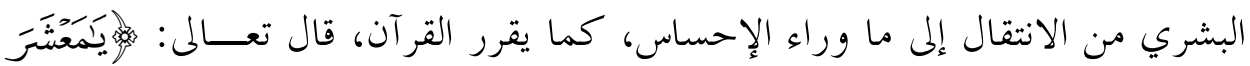

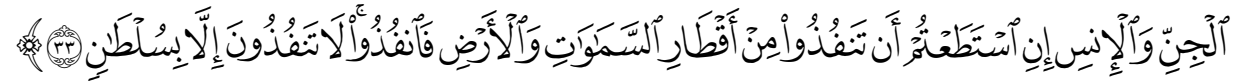

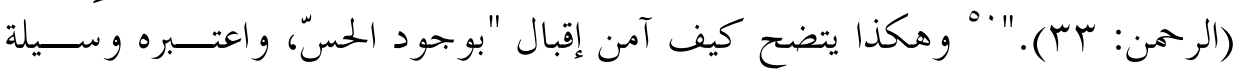

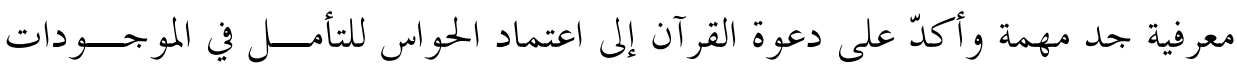

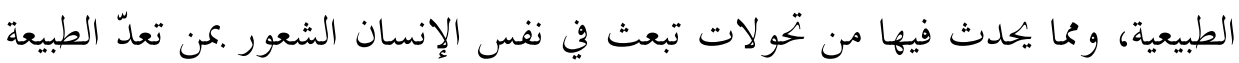

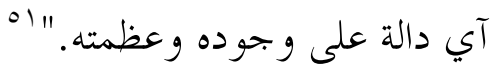

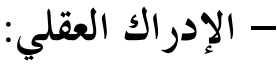

لا يعين إيمان إقبال بالإدراك الحسّي جعله المصدر الوحيد للمعرفة، كما ذهب إلى ذلك السوفسطائيون في الفلسفة اليونانية، أو دعاة المذهب التجريي في الفلسفة الغربية،

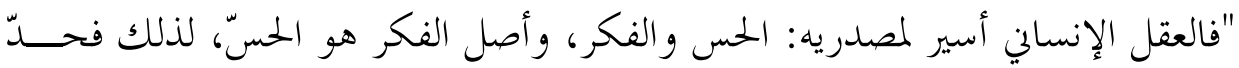
المعرفة هو الحسّ نفسه...وليس للعقل أيّ دور في إنشاء هذا النوع من الأفكار، فدوره

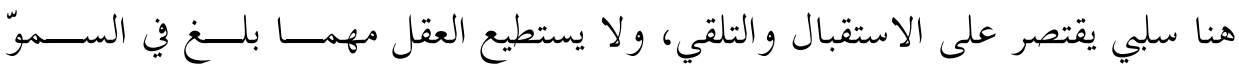

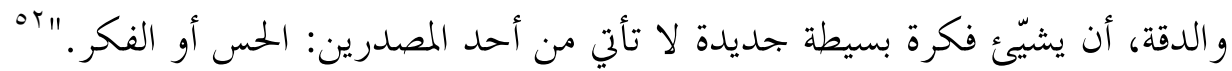
أما إقبال؛ فعدّ الإدراك العقلي مكملاً للإدر اك الحسي، "فتتوقف حياة الإنســـان

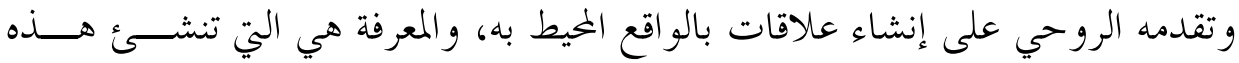

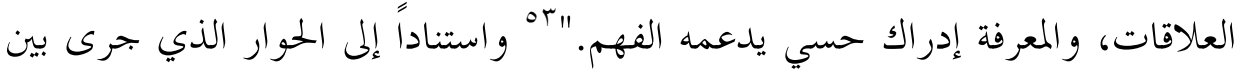

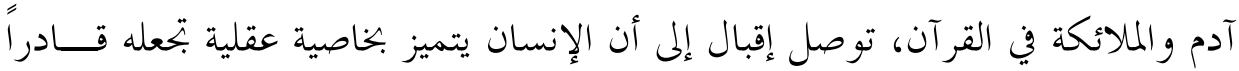

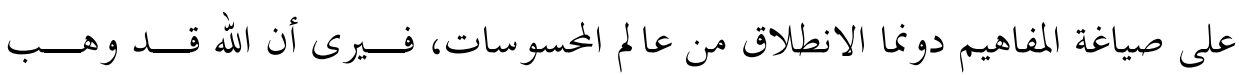
الإنسان "خصيصة تسمية الأشياء، بمعنى تكوين مفاهيم لهذه الأشياء، وتكوين مئمئ مفاهيم

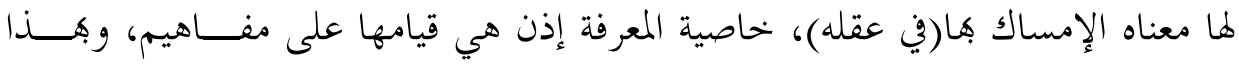

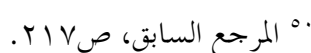

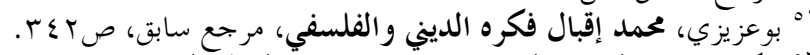

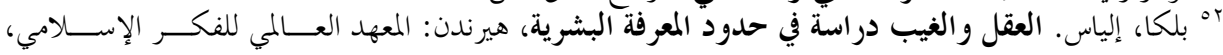




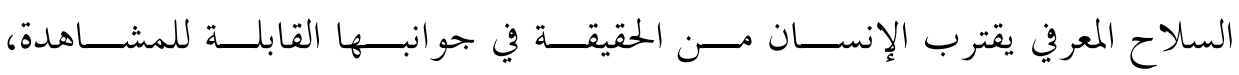
و الملاحظة." "ه وليس المعنى الفلسفي الذي حاول عن طريقه كانط التوفيق بين نظريسـة

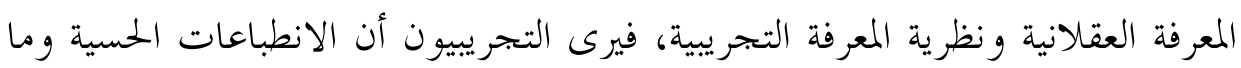

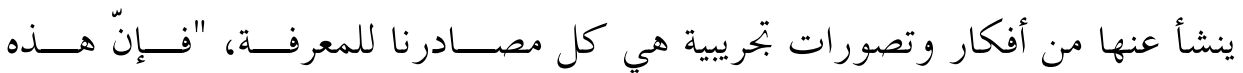

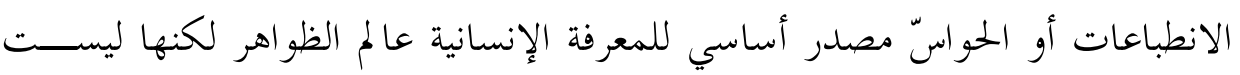

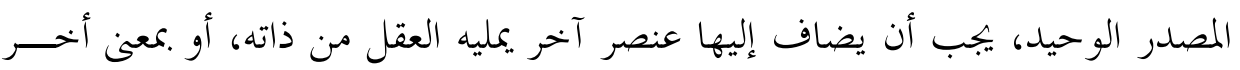

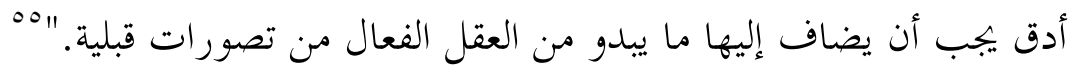

ذلك، أن الصلة بين العقل والحس هلا ما يسندها في الممارسة المعرفية التراثية، وهلا

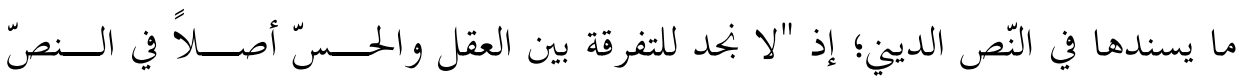

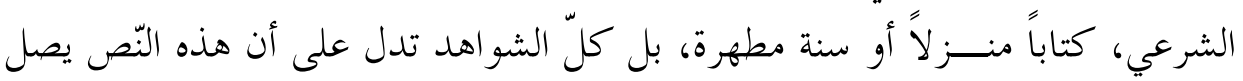

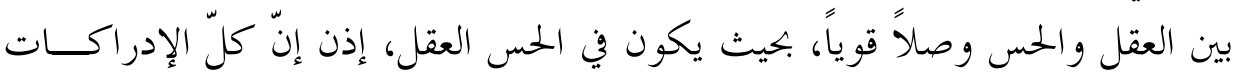

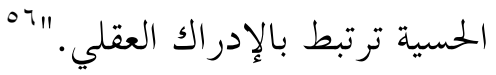

\section{- الإدراك الحدسي: -}

يرى إقبال أنَّ القلب يمكن أن نستخدمه في بحال المعرفة، وليس شرطاً ذلك الفصل

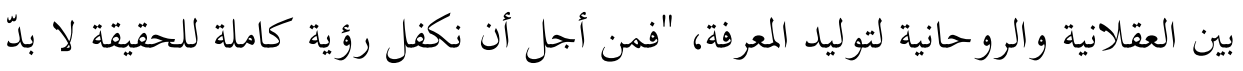

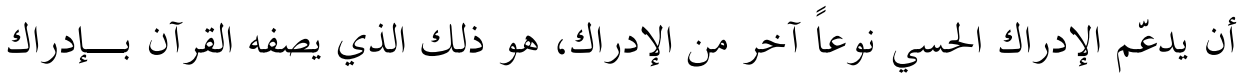

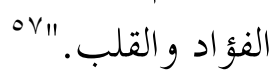

و القلب مثل العقل أداة من أدوات المعرفة، والمعرفة التي مؤتاها القلب تمتلك صفة

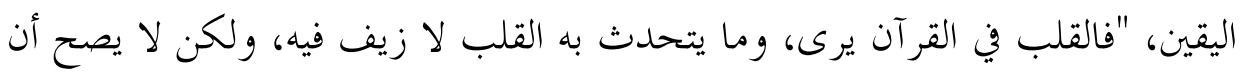

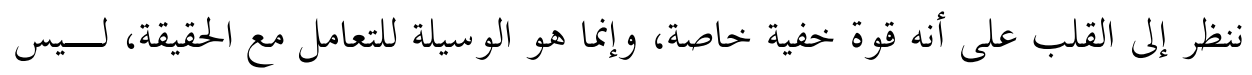

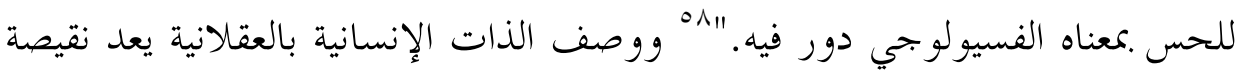

$$
\text { عه المرجع السابق ص بمان. }
$$

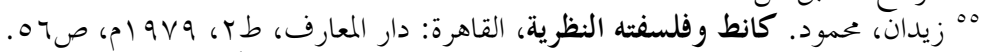

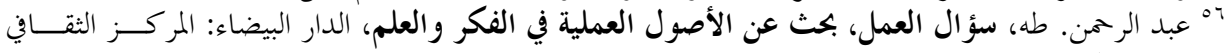

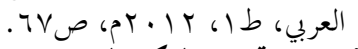

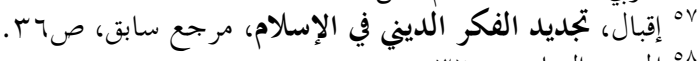




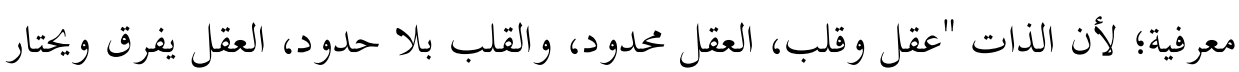

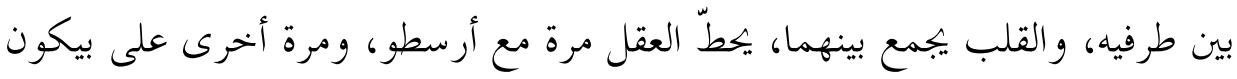

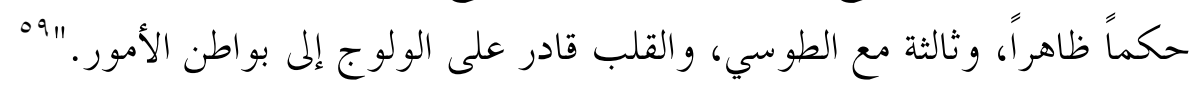

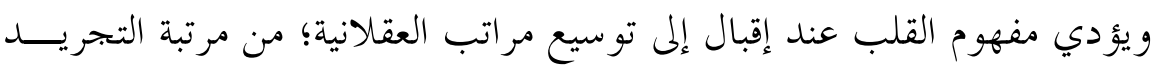

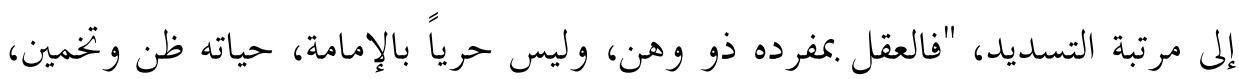

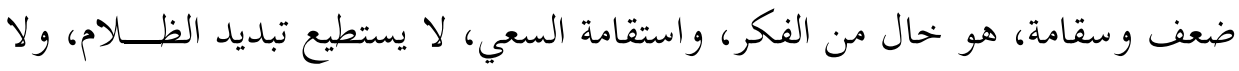

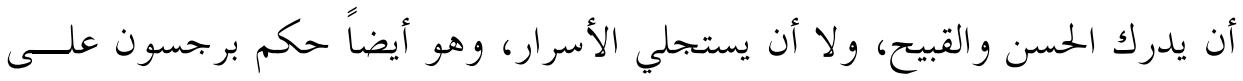

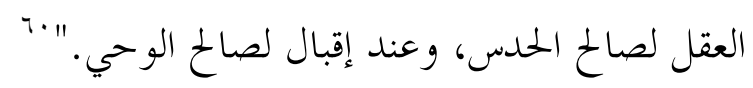

أدخلت العقلانية الغربية الإنسان في مآزق وجودية عددية، فتعرضت إلى نقد حاد

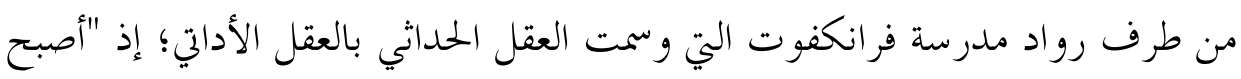

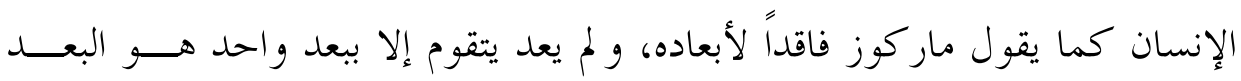

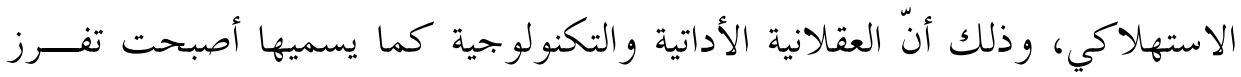

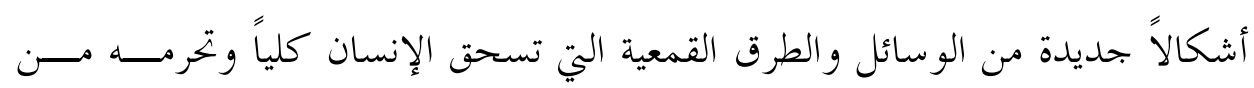

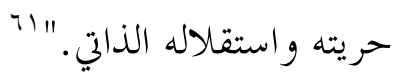

\section{ت. الطبيعة والتاريخ كمصادر للمعرفة في القر آن:}

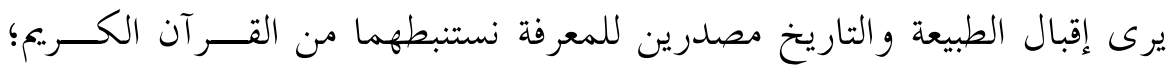

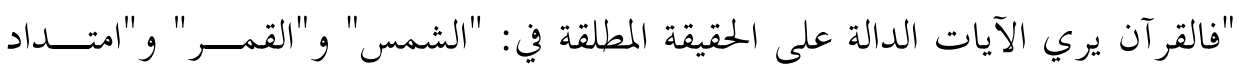

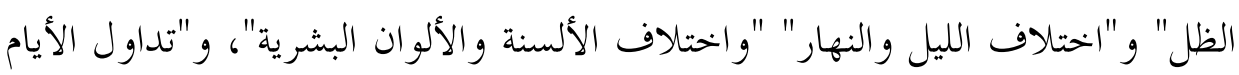

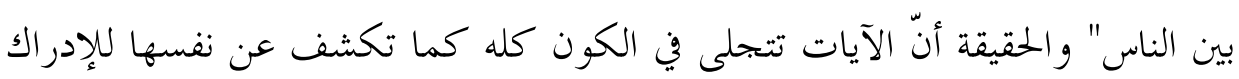

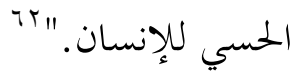

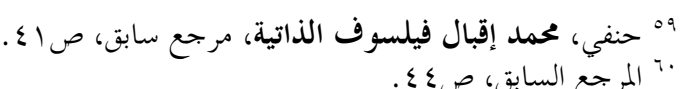

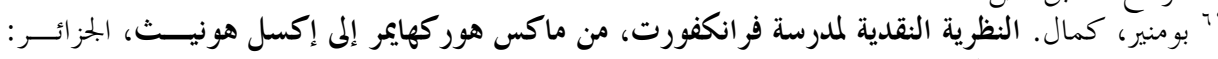


ويرى مهادي كنشلي أن القرآن الكريم، يشير إلى أن هنـــاك مصـــادر معرفيـــة

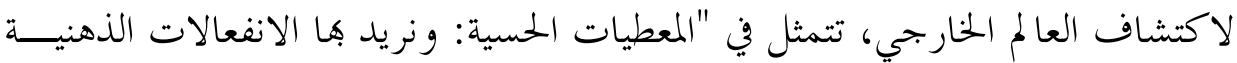

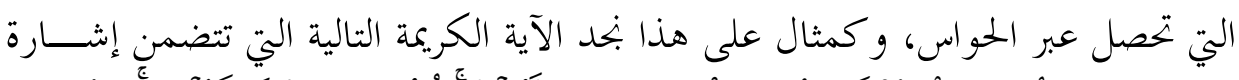

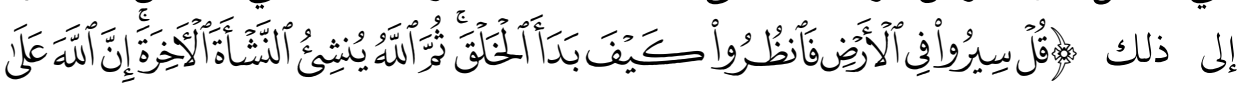

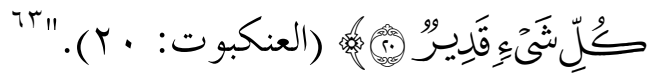

أما المصدر الآخر للمعرفة الذي نستنبطه من القرآن فهو التاريخ؛ "فالتــاريخ -أو

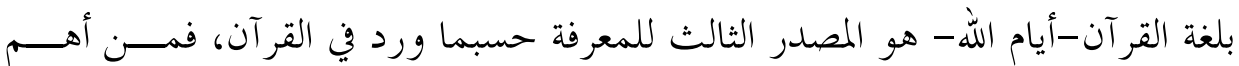

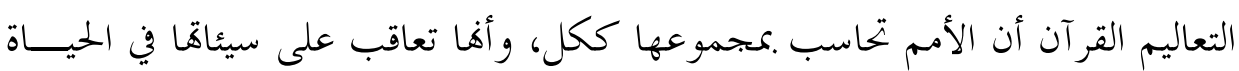

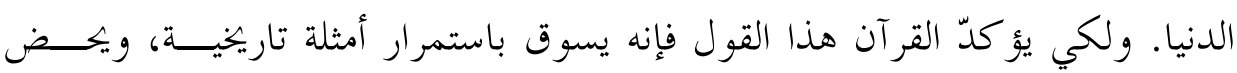

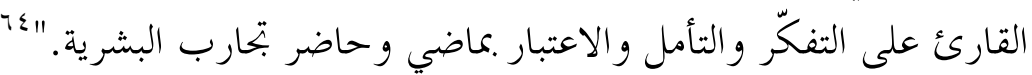
ومن الذين استفادوا من المنهج التاريخي في القرآن، العلّامة ابن خلدون في صياغة

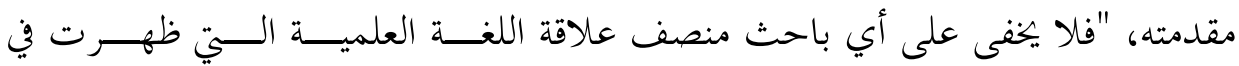

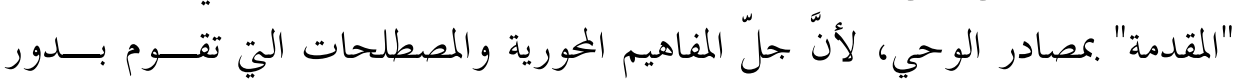

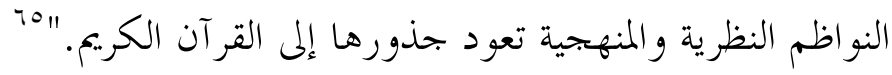

من القواعد المنهجية في الكتابة التاريخية التي استنبطها إقبال من القرآن الكريم؛ هي قاعدة التحقق من صدق الروايات، "لــمّا كانت الدقة في تسجيل ورواية الحقائق التي

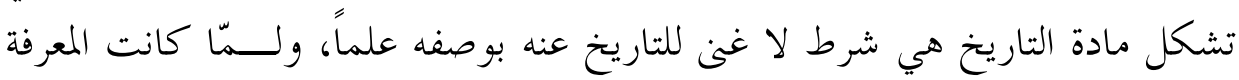

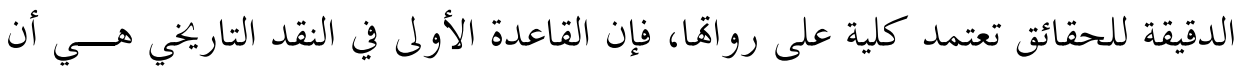

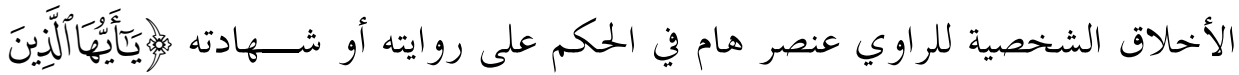

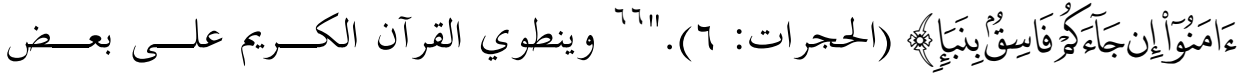

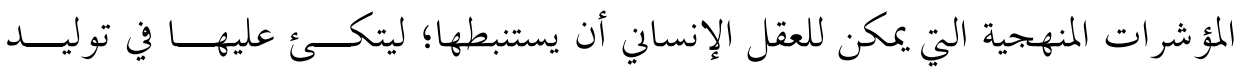

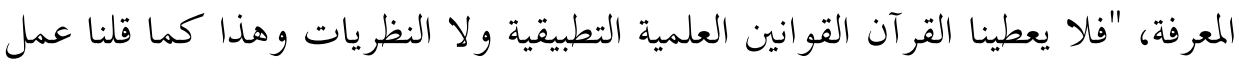

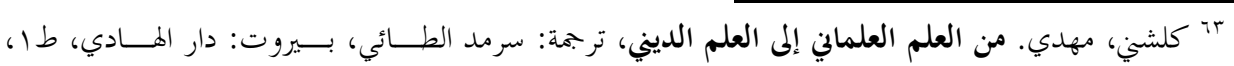

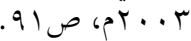

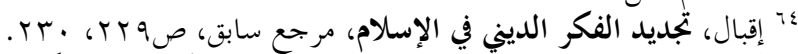

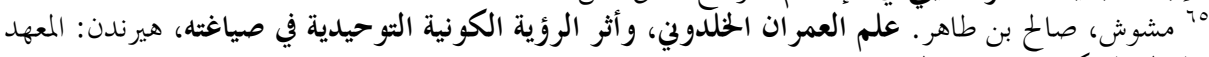

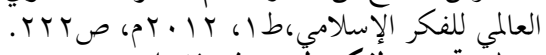

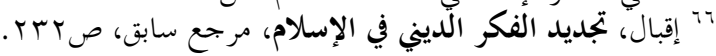




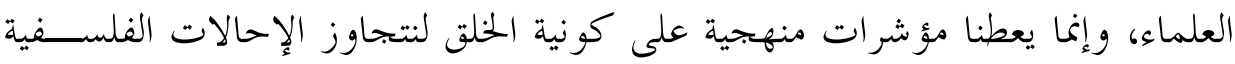

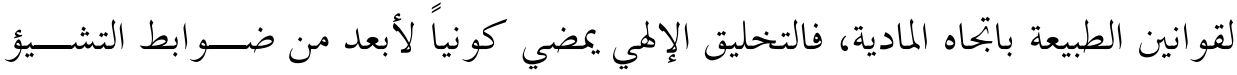

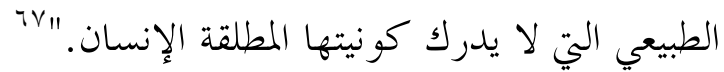

\section{Y ب. التكامل المعرفي عند محمد إقبال:}

إنّ الدلالة الأولى التي أعطيت للتكامل المعرفي لدى العديد من المشتغلين في الفكر

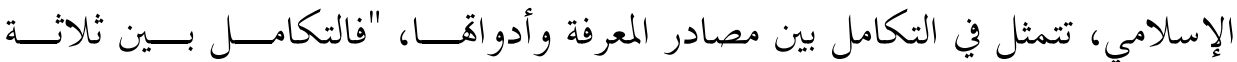

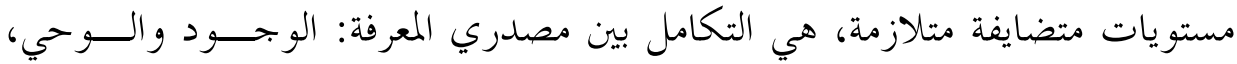

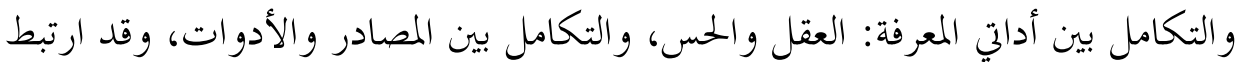

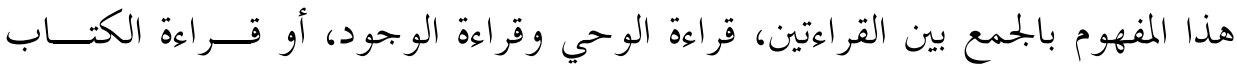

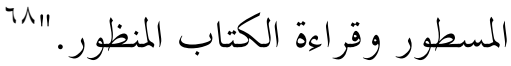

أما الدلالة الثانية للتكامل المعرفي؛ فنجدها في الحقل المعرفي الغربي، لتعين التداخل

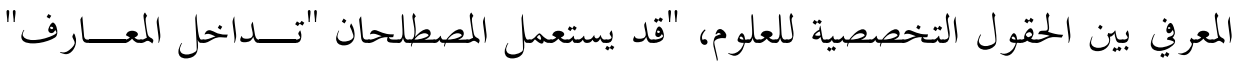
(Interdisplinarite)

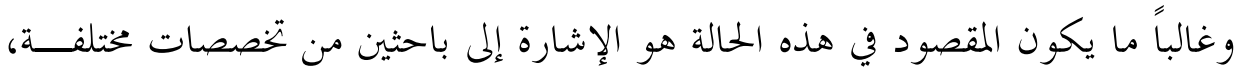

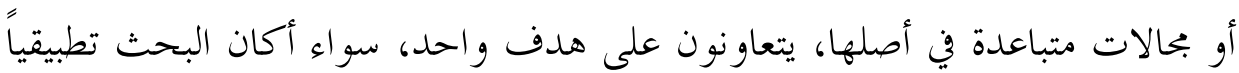

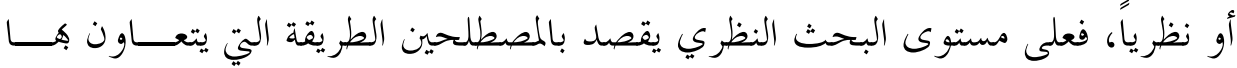
بحموعة من الأكاديميين من تخصصات مختلفة: علماء النفس وأنثربولوجيين و اقتصادين و إعلاميين، لتطوير معرفة واسعة ما أو ظاهرة ما."

ووِّفف التكامل المعرفي في الدلالة الثالثة بصيغة التداخل المعرفي بين العلوم التراثية؛

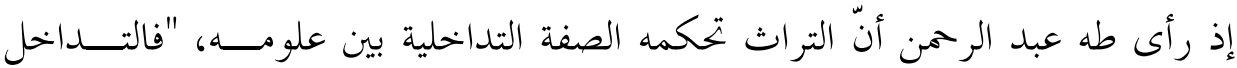

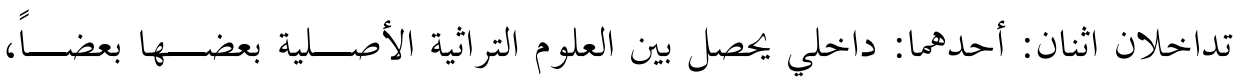
Vآ حاج حمد، محمد أبو القاسم. إبستمولوجية المعرفة الكونية، إسلامية المعرفة والمنهج، بيروت: دار الهـادي،

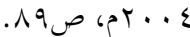

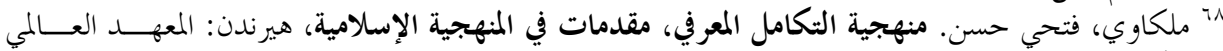

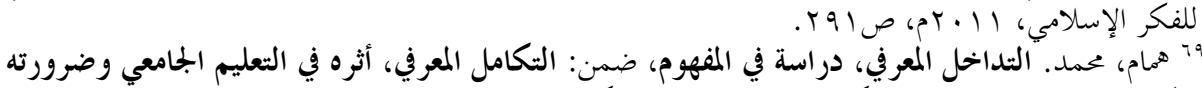

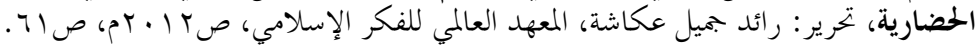




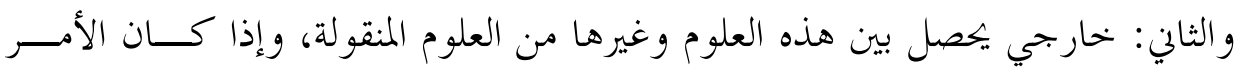

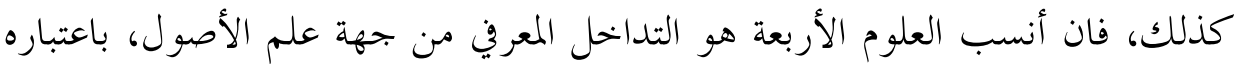
نسيجاً متكاملاً بين معارف فان إسلامية متنوعة، ومن جهة ثانية، الفلسفة الإلهية باعتبارها

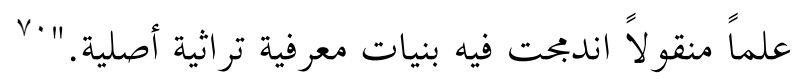

يشير التكامل المعرفي عند محمد إقبال المى العناصر الآتية:

إنّ أهََّّ محدد معرفي للتكامل عند إقبال يتمثل في الرؤية التكاملية للعناصر الوجود،

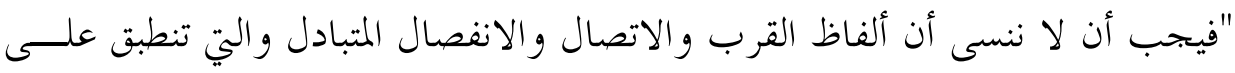

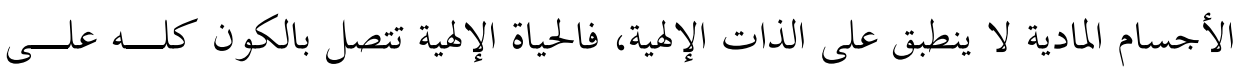

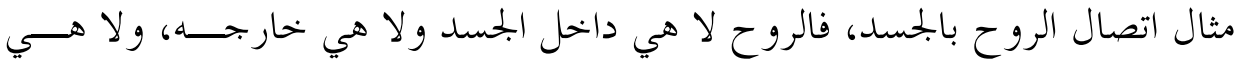

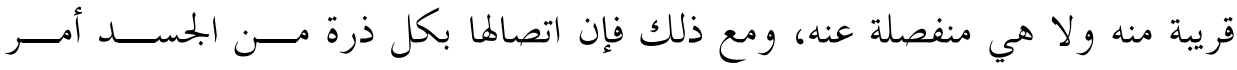

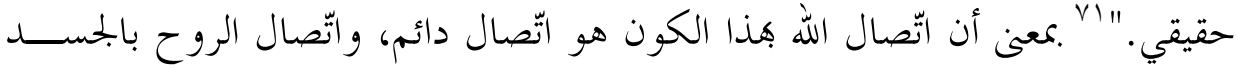

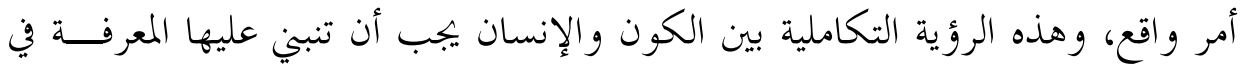

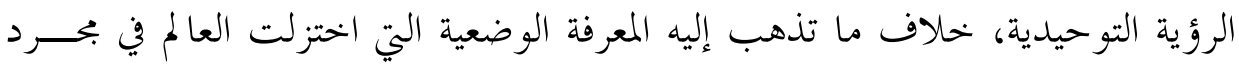

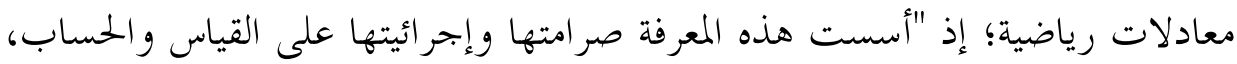

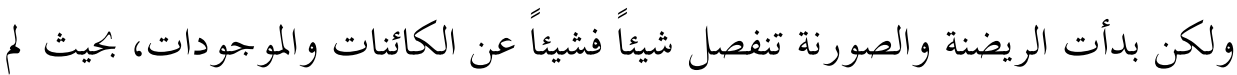

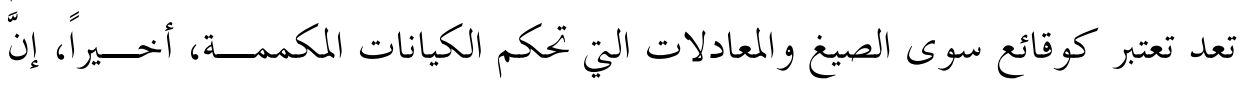
الفكر التبسيطي غير قادر على تمثل الوصل بين الواحد و المتعدد، فإما أنه يوحّد بشكل

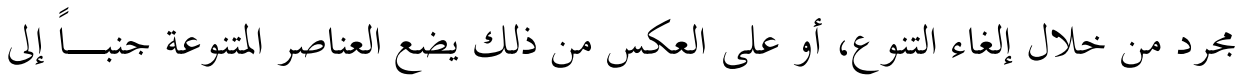

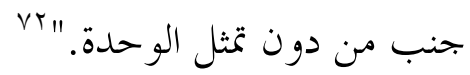

تفضي الرؤية التكاملية لعناصر الوجود إلى وحدة الحقيقة، فيرى إقبال أن العلـــم الطبيعي الذي تطور مع نيوتن في الحضارة الغربية، على الرغم من التقدم الهائل الـــــي

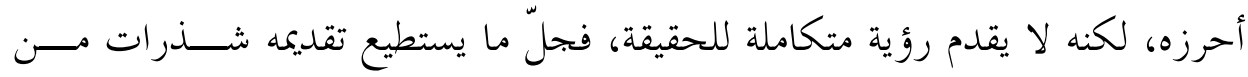

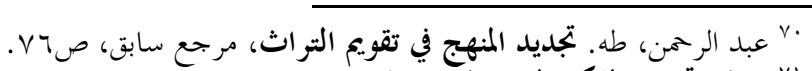

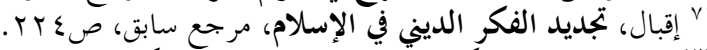

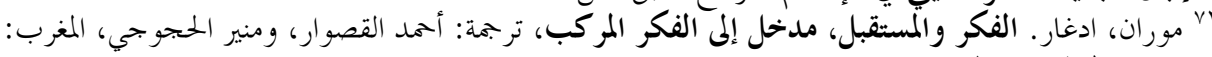


الحقيقة، إضافة إلى تعارضها وتناقضها في كل فترة تاريخية يطور فيها العلـــم أدواتــهـ

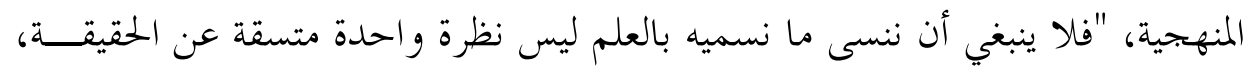

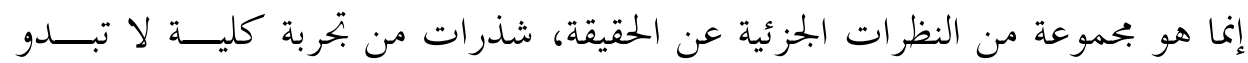
منسجمة مع بعضها البعض. Vr"

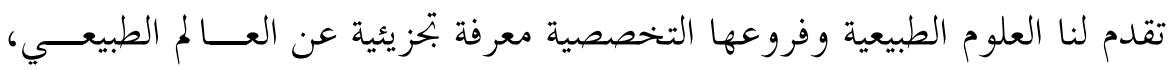
و تفتقد إلى تقديم رؤية متكاملة عن ظواهر العالم الطبيعي، "فالعلم الطبيعي إذن بتزيئي

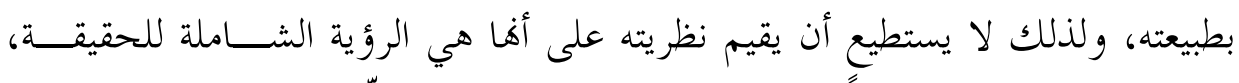

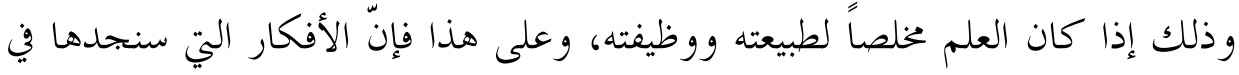

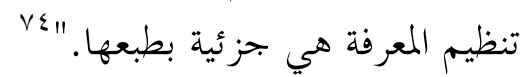

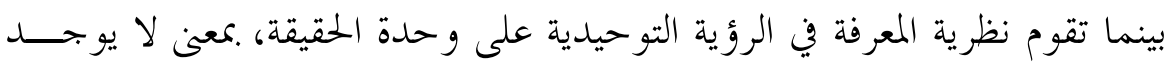

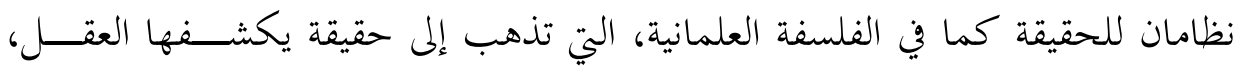

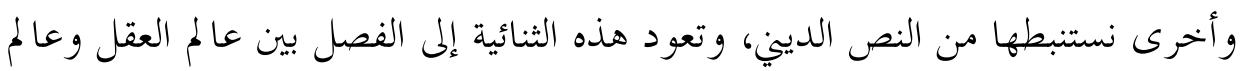

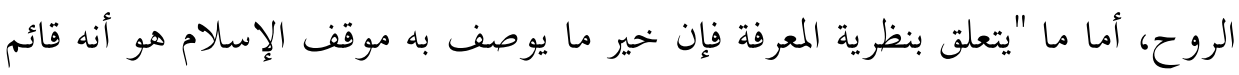

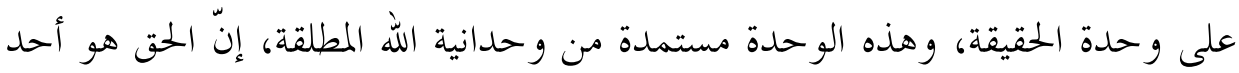

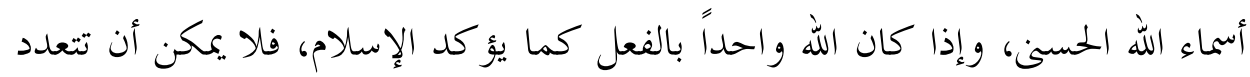

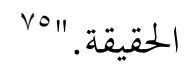

و يرى إقبال أن مبدأ السببية الذي يتسم به المنهج العلمي، أدّى إلى اختزال العــــالم

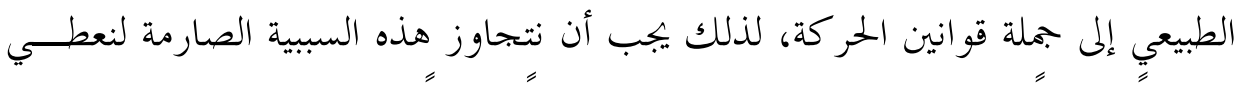

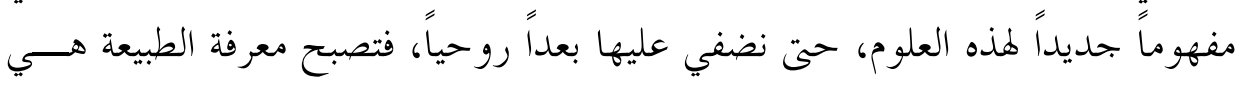

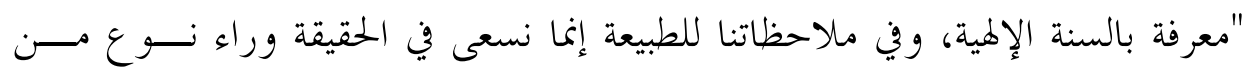

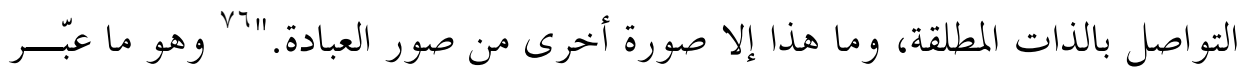

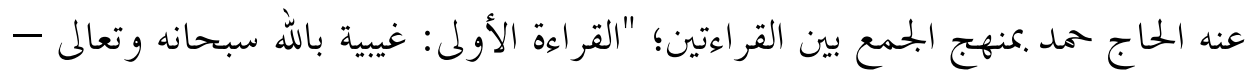

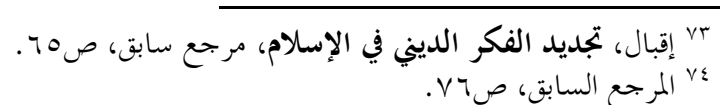

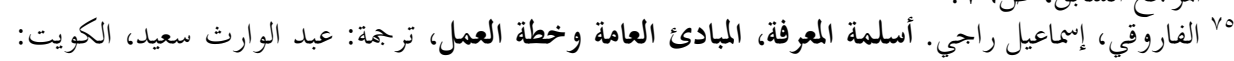




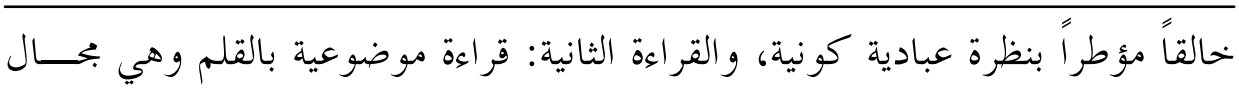

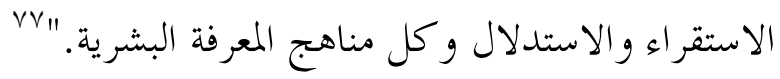

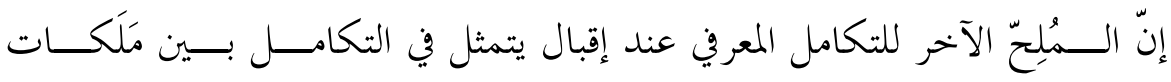

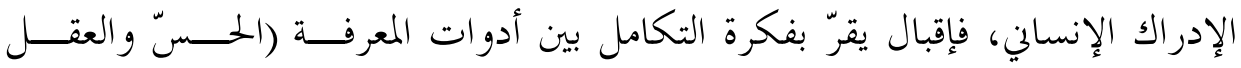
و القلب)، ويعلّ المعرفة الذوقية شأفا شأن المعرفة التجريبية، "فالقر آن وهو يعترف بأن الابتحاه التجريي مرحلة لا يمكن الاستغناء عنها في الحياة الروحية الإنسانية، فانه يعلـــت أهمية متساوية على جميع بحالات التجربة الإنسانية المؤدية إلى معرفة الحقيقـــة، هـــــهـ

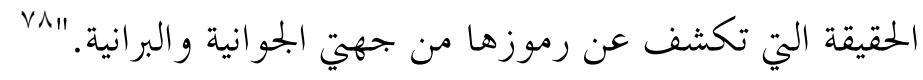

خاتمة:

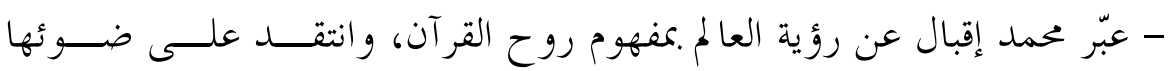

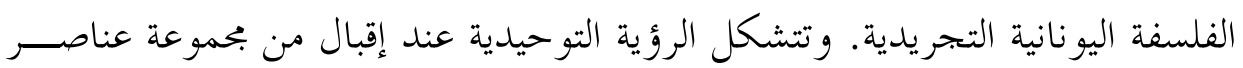

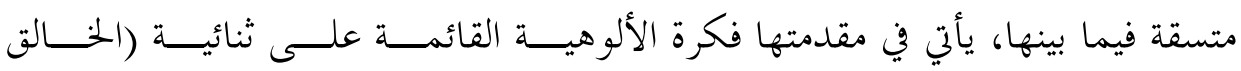

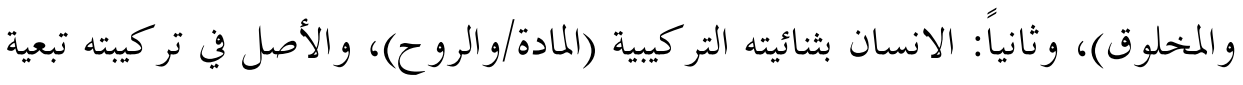

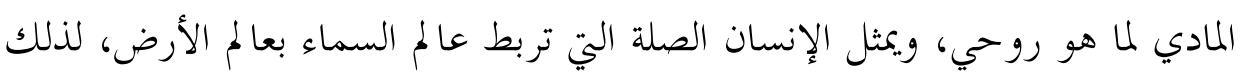
هو مؤتمن على هذا الكون الذي يجيا فيه.

- نستنبط مفهوم التكامل المعرفي عند إقبال معبّرًا عنه بثلاثة أبعاد: الرؤية التكاملية

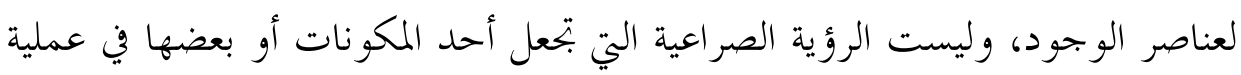

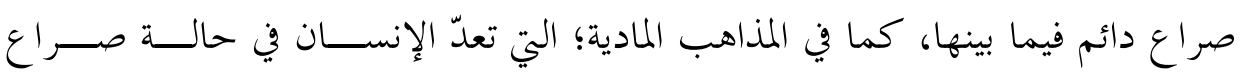

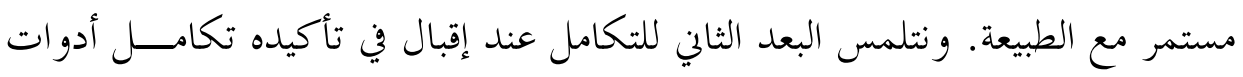

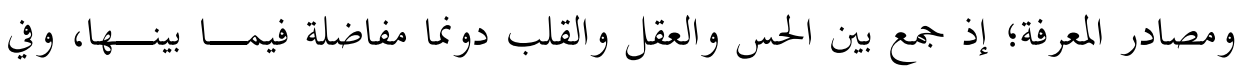

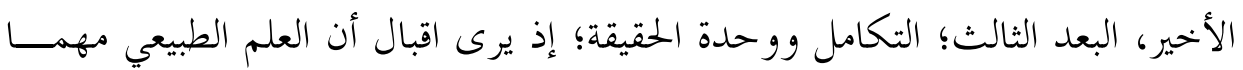

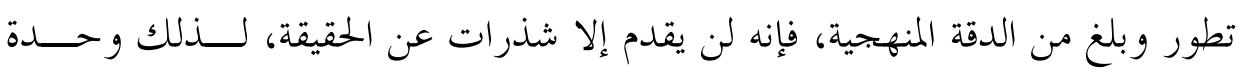
الحقيقة تتكامل فيها معطيات الوحي مع العقل.

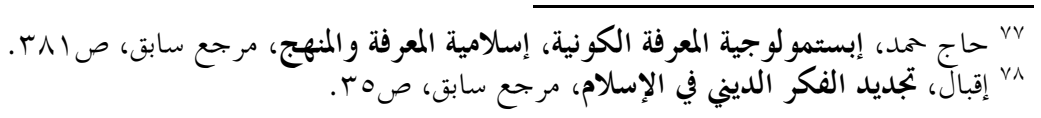

